IZA DP No. 6173

How Does Education Affect the Earnings Distribution in Urban China?

Le Wang

November 2011 


\title{
How Does Education Affect the Earnings Distribution in Urban China?
}

\author{
Le Wang \\ University of New Hampshire \\ and IZA
}

Discussion Paper No. 6173

November 2011

\author{
IZA \\ P.O. Box 7240 \\ 53072 Bonn \\ Germany \\ Phone: +49-228-3894-0 \\ Fax: +49-228-3894-180 \\ E-mail: iza@iza.org
}

\begin{abstract}
Any opinions expressed here are those of the author(s) and not those of IZA. Research published in this series may include views on policy, but the institute itself takes no institutional policy positions.

The Institute for the Study of Labor (IZA) in Bonn is a local and virtual international research center and a place of communication between science, politics and business. IZA is an independent nonprofit organization supported by Deutsche Post Foundation. The center is associated with the University of Bonn and offers a stimulating research environment through its international network, workshops and conferences, data service, project support, research visits and doctoral program. IZA engages in (i) original and internationally competitive research in all fields of labor economics, (ii) development of policy concepts, and (iii) dissemination of research results and concepts to the interested public.
\end{abstract}

IZA Discussion Papers often represent preliminary work and are circulated to encourage discussion. Citation of such a paper should account for its provisional character. A revised version may be available directly from the author. 


\section{ABSTRACT \\ How Does Education Affect the Earnings Distribution in Urban China?*}

China's phenomenal growth is accompanied by both relatively low level of standards of living and high inequality. It is widely believe that investing in education could be an effective strategy to promote higher standards of living as well as to reduce inequality. However, little is known about whether this belief is empirically supported. To this end, we employ a recently developed distributional approach to estimate returns to education across the whole earnings distribution in urban China during economic transition. We find that returns to education are generally more pronounced for individuals in the lower tail of the earnings distribution than for those in the upper tail, in stark contrast to the results found in developed countries. Our result implies that education indeed reduces earnings inequality while increasing individuals' earnings. We also find that the returns to education are uniformly larger for women than for men across the distribution. The results suggest the presence of added effects of education on earnings, as opposed to productivity-enhancing effects, for disadvantaged groups. Finally, we find that rates of educational return increased over time for all parts of the earnings distribution.

JEL Classification: J24, J61, J31, J7, J15, C31

Keywords: returns to education, inequality, gender gap, economic transition, instrumental variable quantile regression

Corresponding author:

Le Wang

Department of Economics

University of New Hampshire

Durham, NH 03824

USA

E-mail: le.wang@unh.edu

\footnotetext{
The author would like to thank Karen Conway, Bruce Elmslie, Richard England, Belton Fleisher, Daniel Lothrop, Jorn-Steffen Pischke, Bei Qin, Chunbei Wang, Bob Woodward, Jeff Zax and seminar participants at the University of New Hampshire, SEA 2010, and AEA 2011 for their comments.
} 


\section{Introduction}

Ever since its economic reforms began in 1978, China has enjoyed stunning economic growth. Despite phenomenal performance at the country level, the economic performance at the individual level remains low, relative to other developed countries. Specifically, China's GDP per capita was 6.3 percent of US's GDP per capita in 1990, 11.6 percent in 2000, and 15.7 in 2005 (Brandt and Rawski, 2008, p.2). Yang et al. (2009) similarly document that in spite of rapid growth in China's manufacturing wage, its absolute level "is only just beginning to be competitive with other developing countries in the region." Moreover, China's phenomenal growth is also accompanied by disturbingly increased inequality. For example, Kanbur and Zhang (2005) find that Gini coefficients increased from $22.4 \%$ in 1952, to 29.3 in 1978 and to $37.2 \%$ in 2000 . Gustafsson et al. (2008, p.1) state that "Income inequality is ... now considered high by international standard. ... [I]n China the speed with which the increase has occurred, and the level to which inequality has risen, is striking."

Investing in education is considered to be an important strategy to promote higher standards of living as well as to reduce inequality in China (Fleisher et al., forthcoming; Heckman, 2003). However, efficiency often arrives at the expense of equity. Can education reduce earnings inequality while increasing individuals' earnings? Who benefits from education most? And how does economic transition from a centralized economy to a market-oriented economy affect the role of education in the labor market? To answer these questions, we need to understand how education affects the earnings distribution. Estimation of the effects of education on the earnings distribution is, however, often complicated by two potential issues.

The first issue is concerned with potential heterogenous impacts of education on the earnings distribution. Not only do we need to know whether education has any positive impact on individuals' earnings; we also need to know whether education affects individuals differently across the earnings distribution. Previous empirical studies have typically relied on regression analysis and standard linear specification, thereby focusing mainly on average effects. While of interest, the average effects may mask much important information in the rest of the earnings distribution 
and may not be informative as to the inequality-reducing effects of education. For example, if the effects are more pronounced in the upper tail of the earnings distribution than they are in the lower tail, education increases inequality rather than decreases it. In order for education to necessarily promote equality, education should increase earnings more for individuals in the lower tail of the earnings distribution than for those in the upper tail. If the average effects were the only information available, it is not clear whether or not expanded educational opportunities will increase or decrease inequality.

The second issue concerns the causal effects of education on earnings. There is little doubt that education plays an important role in determining individuals' earnings. Estimation of the causal earnings effects of education, however, is not trivial due to potential endogeneity and measurement error problems. For example, abler individuals may acquire more education as well as earn more in the labor market; the observed positive relationship between education and earnings may be simply driven by a third variable, namely ability. Moreover, information on the schooling variable in survey data may also be misreported. Failure to sufficiently control for (both observable and unobservable) determinants in estimation may thus preclude us from drawing any meaningful causal inference of the underlying effects of education on earnings.

In this paper, we address these two issues by estimating the causal heterogeneous returns to education across the earnings distribution in China. In particular, we employ recently developed instrument variable quantile regression (IVQR) approach to estimate rates of return within a distributional framework. Our paper is not the first paper to examine the issue of heterogeneity, and the previous literature has utilized ordinary quantile regression for this purpose. However, as we shall see below in the section of literature review, such analysis is limited in the Chinese context. More important, this type of studies ignore the issue of endogeneity, thereby failing to uncover the meaningful causal effects of education at the distributional level. Our paper thus fills the gap in the literature. Solving heterogeneity and endogeneity problems together poses a much greater challenge to the estimation of returns to education than is solving each problem separately; it is not straightforward to allow for endogenous variables within a nonlinear model, even if a valid 
instrument variable is available. ${ }^{1}$ The IVQR approach proposed by Chernozhukov and Hansen (2008) allows us to uncover heterogeneous effects across the earnings distribution and to take into account the endogeneity problem, thereby enabling us to answer the question posed above: how does education affect the earnings distribution? In order to focus on the heterogeneity problem, we borrow a typical IV from the existing literature - spousal education - in our analysis so as to circumvent the potential endogeneity and measurement error problems (e.g. Trostel et al., 2002; Arabsheibani and Mussurov, 2007). While we do not propose a novel IV in the analysis, we employ the recently developed method by Conley et al. (Forthcoming) to assess the empirical validity of our IV within the Chinese context. The idea behind this is to assess how sensitive our inferences of rates of return are to varying degrees of violation of the exogeneity or exclusion restriction assumption. If the conclusion remains unchanged, our results are considered to be robust and the IV plausibly exogenous. Our sensitivity analysis shows that our IV is indeed plausibly exogenous, and that the results are not sensitive to the relaxation of the exogeneity assumption. We believe that this exercise itself is of use for similar studies.

To perform our analysis, we utilize data from the China Household Income Project (CHIP) 1995 and 2002. As noted in Wang et al. (2009), the 1995 and 2002 samples represent different stages of economic transition initiated in China. Economic transition was still in a relatively early stage in 1995, and moved into a more mature stage in 2002. Compared to the previous literature using the ordinary quantile regression approach, we provide a dynamic perspective on the progress of economic transitions as well as its impacts on the labor market in China. Our results are striking, reaching three main conclusions. First, consistent with the existing literature, we find large, positive returns to education after instrumenting for education; the 2SLS estimates are much larger than their OLS counterparts. Second, we uncover a large degree of heterogeneity in returns to education across the earnings distribution, as well as across gender. In particular, gains are more pronounced for individuals in the lower tail of the earnings distribution than for those in the upper tail, and are uniformly larger for women than for men across the whole distribution. In

\footnotetext{
${ }^{1}$ Patrinos et al. (2006) briefly review the literature, pointing out that only a few empirical studies have addressed these two problems simultaneously, and that none exists in the Chinese context.
} 
our view, one possible explanation for the results is that there exist added effects of education for disadvantaged groups, in addition to productivity-enhancing effects of education. For the less able individuals, education could increase their ability to migrate to better places for better jobs. For women, education may decrease factors contributing to the gender gap such as discrimination in the labor market. Finally, we find that rates of educational return increased for all parts of the earnings distribution over time. We take this result as evidence for increased overall demand for a skilled labor force resulted from economic reforms.

Our results have important policy implications. First, despite the Chinese government's stated commitment to increase its spending in education, the investment in education, although increased, remains relatively low. China's investment in schooling accounted for only about $2.5 \%$ of its GDP in 1990 s and $3.32 \%$ in 2002, still far below the world average of $4.8 \%$ (Liu and Yuan, 2007). If the small rates of returns to education suggested by the OLS estimates in the prior studies justifies the low level of investment in education, our IV estimates suggest the opposite - the low level of investment is not justified and could retard economic growth, calling for increased investment in education. Second, our results suggest that education could be an effective way to promote both efficiency and equality in China. Not only does education increase individuals' earnings; but it also increases the earnings of the least earners more than others for both males and females, thereby shrinking the earnings gap among males as well as among females. Furthermore, that education benefits females more than males in the labor market suggests that promoting a higher level of education can also mitigate the increasing gender gap during economic transition.

While in this paper we focus on estimating the returns to education in China, we believe that our research also contributes to the literature outside of the Chinese context along many dimensions. First, our results contrast with the results for developed countries. For example, Martins and Pereira (2004) find that schooling increases income inequality in 16 developed countries. The stark difference suggests that education plays a very different role for individuals in the developing countries than for those in the developed countries. Understanding different roles of education in different countries is vital for understanding individuals' decisions on human capital 
accumulation, which in turn affects economic growth at the macro level. In the paper, we also discuss the distinct features of the Chinese educational system and labor market structures may help explain the observed difference between our results and those reported in the developed countries. Second, our results imply that education can potentially play an even larger/smaller role in explaining earnings inequality as well as the gender gap than previously found in the literature, depending on the size and pattern of returns to education across the earnings distribution. Given the evidence of heterogeneous returns to education, earnings inequality and the gender gap could be explained by the differences in human capital as well as its returns. Finally, our paper contributes to a growing literature estimating heterogeneous effects of education. For example, Harmon et al. (2003) utilize random-coefficient models to estimate the variance of returns to education in UK, whereas Koop and Tobias (2004) introduce various Bayesian hierarchical models to investigate the nature of unobserved heterogeneity in returns to schooling in the U.S.. Relaxing distributional and functional form restrictions, Henderson et al. (Forthcoming) employ generalized nonparametric kernel estimation to estimate heterogenous rates of return across different demographic groups in the U.S.. Here, we focus on a particular heterogeneity - the heterogeneity across the earnings distribution. By illustrating an application of the IVQR approach within the Chinese context, our paper highlights the importance in looking beyond the average causal effects of the variables of main interest in empirical analysis.

The rest of the paper is organized as follows. Section 2 briefly reviews the related literature; Section 3 presents the empirical methods employed; Section 4 describes the data; Section 5 provides an evaluation of the empirical validity of the instrument variable; Section 6 discusses the results, and Section 7 concludes.

\section{Literature Review}

The increased availability of Chinese data has led to a growing literature estimating rates of return to education in China. The prior studies generally find that there exists a large, positive effect 
of education on earnings and that the returns to education becomes larger in more recent years, although the actual estimates differ due to differences in the identification strategies employed and the data utilized. However, most previous empirical studies have typically focused on mean effects of education on earnings in China, and the issue of heterogeneity is often ignored. Thus, the questions - who benefits from education most and whether the pattern has changed during economic transition - remain unanswered. A recent exception is Patrinos et al. (2006). Patrinos et al. (2006) examine the effects of education at different parts of the earnings distribution for 16 East Asian and Latin American countries, including China. They find that the rates of return decrease with quantiles in China, implying that education could decrease economic inequality. However, Patrinos et al. (2006) employ ordinary quantile regression in their analysis which does not account for the potential endogeneity problem; no causal inference could thus be drawn from their results. Moreover, the authors utilize only the data from China Economic, Population, Nutrition and Health Survey 2000; the results found in their paper do not provide a complete picture of how the effects of education on the earnings distribution change during economic transition.

As mentioned above, potential endogeneity and measurement error problems also complicate the estimation of returns to education. The point estimates from earlier studies that typically utilize the ordinary least squares (OLS) approach are susceptible to endogeneity and measurement error bias. It is thus not surprising that Li et al. (2005) states that "Despite the rapid accumulation of evidence on the returns to education in China, no study has yet established causality". Several more recent studies have attempted to circumvent the endogeneity problem by employing instrument variable approach (for example, Heckman and Li, 2004; Fleisher et al., 2005; Li and Luo, 2004; Chen and Hamori, 2009;). Given the importance of isolating the causal effects of education, it is thus important to review different identification strategies employed in the literature.

Heckman and Li (2004) use an IV strategy based on parental education and year of birth. Both year of birth and parental education may themselves have an impact on individuals' earnings. For example, Chen and Feng (2009) find, conditioning on one's own education, both father's and mother's education have independent effects on one's earnings. Year of birth could also capture 
the cohort effects that directly impact individuals' wages. Li and Luo (2004) use as IVs family

background characteristics as well as the presence of boys in the household. Similarly, family background characteristics may not satisfy the exclusion restriction for an IV. A more recent study by Chen and Hamori (2009) uses spousal education as their identifying instrument, which we borrow in our analysis. This identifying strategy is based on positive assortative matching in the marriage market; spousal education is positively correlated with an individual's education but does not directly affect his or her earnings. While this exclusion restriction could also be considered onerous, this IV works well in the Chinese context, as we shall show below. A notable, recent study by Li et al. (2005), instead of relying on external IVs, takes another avenue to circumvent the endogeneity problem. In particular, they utilize a large Chinese twins dataset that allows them to correct for measurement error, ability, and family background characteristics that are independent over time. However, even so, the twins-data approach may still fail to control for time-varying characteristics such as motivation.

To summarize, while recent literature has put great efforts to isolate the causal average effects of education on earnings, very little is known about how education affects the earnings distribution in China. We now turn to the empirical methods employed in our analysis.

\section{Empirical Methods}

To estimate the returns to education in China, we utilize two types of estimation techniques: (1) mean approach, and (2) distributional (quantile) approach. Since the instrument variable quantile approach (IVQR) is a relatively new method in the econometric literature, we briefly describe the method along with other methods used to ease the comparisons and discussions below.

\subsection{Mean Approach}

To begin, we consider the following (augmented) Mincer wage equation ${ }^{2}$

\footnotetext{
${ }^{2}$ There are a number of ways to estimate rates of return. For example, Heckman et al. (2008) advocate a computation involving option values. Polachek (2008) reviews the literature and concludes that the Mincer earnings
} 


$$
\mathbb{E}\left[\ln \left(w_{i}\right)\right]=\beta_{0}+\beta_{1} S_{i}+\beta_{2} E_{i}+\beta_{3} E_{i}^{2}+\text { Minor }_{i} \beta_{4}+\text { Age }_{i}^{\prime} \beta_{5}+\text { Province }_{i}^{\prime} \beta_{6}
$$

where $w_{i}$ is an individual's earnings; $S_{i}$ is years of schooling, and $\beta_{1}$ is the parameter of interest - returns to education; $E_{i}$ is working experience, and $E_{i}^{2}$ working experience squared; Minor $_{i}$ is a dummy variable indicating an individual's minority status; $A g e_{i}$ is a set of age group dummy variables, and Province $_{i}$ a set of provincial dummy variables. ${ }^{3}$ As most studies do, we exclude various determinants of earnings such as tenure, occupation and sectors from the estimation, as these variables are potentially endogenous variables that could be determined by schooling; that is, these variables themselves could be the reasons why education affects individuals' earnings. ${ }^{4}$ We thus condition on only exogenous variables here to simplify the interpretations of returns to education.

We estimate (1) by Ordinary Least Squares (OLS) and Two Stage Least Squares (2SLS) methods. The OLS provides a consistent estimate of returns to education only if $S$ is uncorrelated with the error term in the log wage equation. The consistency of the 2SLS estimates hinges on the availability of an instrument $Z$ that is exogenous to the disturbance term and correlated with $S$. The IV and its validity are discussed below.

One estimation issue warrants further discussions. The recent development in the weak-IV literature suggests that instruments $Z$ have to be sufficiently linearly related to $S$. This assumption is crucial because when instruments are only weakly correlated with the endogenous variables, 2SLS estimates are biased toward OLS estimates and inference is not reliable (e.g. Bound et al.,

function approach has become the norm since Mincer's 1974 seminal work. To facilitate comparisons with the previous studies, we choose the Mincer earnings function approach here.

${ }^{3}$ We include these age dummies to capture potential cohort effects, since there were several nation-wide events in China that affected the educational attainment of school-aged children; for example, during the period of Chinese Cultural Revolution, schools were closed in many urban areas, which resulted in widespread disruption of education of school-aged children (see, e.g. Giles et al. (2004) for more detailed discussion of Cultural Revolution). We, however, do re-estimate all the results excluding age dummies, and the conclusions remain the same. The results are omitted but available upon request.

${ }^{4}$ For example, firm-specific skills (usually measured by tenure) could be an important determinant of individual earnings. However, it could be potentially determined by schooling. For example, Knight and Yueh (2004) find that schooling is an important determinant of job mobility, which is in turn negatively related to the length of job tenure. Therefore, like many other important determinants of earnings such as occupations and industries, job tenure is excluded in estimations. 
1995; Staiger and Stock, 1997). Hence, we conduct two tests (F-test and Kleibergen-Paap rk Wald statistics) to assess the relevance of our instruments below.

\subsection{Distributional Approach}

To simplify the notations, let $X_{i}$ denote all other covariates $\left(\left[1, E_{i}, E_{i}^{2}\right.\right.$, Minor $_{i}$, Age $_{i}$, Province $\left.\left._{i}\right]\right)$ in the wage equation. To allow for heterogenous effects of education on earnings, we consider the following $\tau$-th conditional quantile wage function

$$
Q_{\ln \left(w_{i}\right)}\left(\tau \mid X_{i}, S_{i}\right)=X_{i} \alpha(\tau)+\beta_{1}(\tau) S_{i}
$$

where $\alpha(\tau)$ is the returns to $X_{i}$ for individuals at the $\tau$-th quantile, and $\beta_{i}(\tau)$ the returns to ecducation; $\tau \in(0,1) \mapsto X_{i} \alpha(\tau)+\beta_{1}(\tau) S_{i}$ is strictly increasing and continuous in $\tau$. Comparing (1) and (2), we notice that the returns to education is a function of $\tau$ and now allowed to vary with $\tau$. It is worth mentioning that $\tau$ is generally interpreted as individual ability in the literature (e.g. Chernozhukov and Hansen (2008); Mwabu and Schultz (1996); Arias et al. (2001)).

\subsubsection{Ordinary Quantile Regression}

Suppose that the error term in the log wage equation is independent of $X, S$. Koenker and Bassett (1978) propose to estimate $\alpha(\tau), \beta_{1}(\tau)$ in $(2)$ by solving the following minimization problem:

$$
Q_{\ln (w)}\left(\tau \mid X_{i}, S_{i}\right)=\underset{\alpha(\tau), \beta_{1}(\tau)}{\operatorname{argmin}} \mathbb{E}\left[\rho_{\tau}\left(\ln \left(w_{i}\right)-X_{i} \alpha(\tau)-\beta_{1}(\tau) S_{i}\right]\right.
$$

where $\rho_{\tau}:=(\tau-1[u<0]) u$. Under weak conditions, the resulting estimator is (asymptotically) normally distributed (see Koenker, 2005 for details). In practice, the problem is solved via linear programming techniques and implemented by -qreg- in Stata. We bootstrap the standard errors based on 500 replications to improve finite sample performance. 


\subsubsection{Instrument Variable Quantile Regression}

The exogeneity assumption that the error term in the log wage equation is independent of $X, S$ may be too stringent for a number of reasons discussed above; we may thus want to relax this assumption to account for potential dependence between the error term and educational attainment. To this end, we employ the recently developed instrument variable approach proposed by Chernozhukov and Hansen (2008). The identification of this interesting approach again relies on the existence of instrument variables $Z$ that are statistically related to $S$. Moreover, $X, Z$ are independent of the error term. These assumptions imply an important moment restriction to obtain the IVQR estimator:

$$
\begin{array}{r}
\mathbb{P}\left[\ln (w) \leq Q_{\ln (w)}(\tau \mid X, S) \mid X, Z\right]=\tau \\
\mathbb{P}\left[\ln (w)-X \alpha(\tau)-\beta_{1}(\tau) S \leq 0 \mid X, Z\right]=\tau
\end{array}
$$

The moment condition (4) implies that 0 is the $\tau$-th conditional quantile of $\ln (w)-X \alpha(\tau)-$ $\beta_{1}(\tau) S\left(\operatorname{as} Q_{\ln (w)}(\tau \mid X, S)\right.$ is the $\tau$-th conditional quantile of $\left.\ln (w)\right)$. Thus, Chernozhukov and Hansen (2008) cleverly formulate the IVQR problem as finding $\left(\alpha(\tau), \beta_{1}(\tau)\right)$ so that 0 is the solution to the conditional quantile of $\ln (w)-X \alpha(\tau)-\beta_{1}(\tau) S$ on $X, Z$ :

$$
0=\underset{\lambda(\tau)}{\operatorname{argmin}} \mathbb{E}\left[\rho_{\tau}\left(\ln \left(w_{i}\right)-\beta_{1}(\tau) S_{i}-X_{i} \alpha(\tau)-\widehat{Z}_{i} \lambda(\tau)\right]\right.
$$

where $\widehat{Z}_{i}$ is a linear projection of $S_{i}$ on $X_{i}, Z_{i}$ in practice. Equation (5) implies that the estimates of $\beta_{1}(\tau)$ should drive the estimates of $\lambda$ as close to 0 as possible in ordinary quantile regression. In practice, the estimation involves the following steps:

1. For a given value of $\beta^{i}(\tau)$, run the ordinary $\mathrm{QR}$ of $\ln \left(w_{i}\right)-\beta^{i}(\tau) S_{i}$ on $X_{i}$ and $\widehat{Z}_{i}$ to obtain the estimates $\widehat{\alpha}\left(\beta^{i}(\tau), \tau\right), \widehat{\lambda}\left(\beta^{i}(\tau), \tau\right)$

2. Test $\widehat{\lambda}\left(\beta^{i}(\tau), \tau\right)=0$ and save the corresponding Wald statistic, $W^{i}$. 
Repeat (1)-(2) for all the values in a pre-specified support for $\beta^{i}(\tau) .{ }^{5}$ And the value that minimizes $W$ is the IVQR estimate ${\widehat{\beta_{1}(\tau)}}^{I V Q R}$ and the corresponding $\widehat{\alpha}\left(\beta^{i}(\tau), \tau\right)$ is the IVQR estimate of $\alpha(\tau)$. Let $\widehat{\delta(\tau)}^{I V Q R} \equiv\left(\widehat{\alpha(\tau)}^{I V Q R},{\widehat{\beta_{1}(\tau)}}^{I V Q R}\right)^{\prime}$. Under appropriate regularity and identification conditions, the resulting estimator $\sqrt{N}\left(\widehat{\delta(\tau)}^{I V Q R}-\delta(\tau)\right) \sim \mathbb{N}\left(0, A^{-1} B A^{-1}\right)$, where $A \equiv \mathbb{E}\left[f_{\epsilon}(0 \mid \tilde{X}, Z) \tilde{X}^{\prime} \tilde{X}\right] ; B \equiv \tau(1-\tau) \mathbb{E}\left[(X, Z)(X, Z)^{\prime}\right]$. See Chernozhukov and Hansen (2008) for more details of the estimation of $A$ and $B$. In addition, Chernozhukov and Hansen (2008) also propose a dual inference approach that is robust to weak IV. We implement this approach as well; the results, however, do not change and are thus omitted but available from the authors upon request.

\subsubsection{Measurement Errors}

Prior to continuing, two issues regarding measurement errors are worth noting. First, Schennach (2008) points out that in the presence of measurement error in the endogenous variable (schooling in our case), the exogeneity assumption of the IV may not hold for general nonparametric or nonseparable models. Specifically, due to the nature of the non-separablity, the error term could be dependent on the endogeneou variable, and as a result, dependence between the error term and the IV arises through the underlying endogenous variable. This is, however, not the case in our analysis. In this paper, we follow the literature by assuming linear quantile regression functions. Schennach (2008, p.1011) notes that the exogenity assumption is still satisfied when the quantile function is linear in both regressors and error term. ${ }^{6}$ A natural question then arises: is the linearity

\footnotetext{
${ }^{5}$ Given the computational complexity of the IVQR approach, in practice, we utilize a plausible support from -0.05 to 0.3 in increments of 0.001 ; that is, we consider as plausible the interval in which the smallest returns to education are $-5 \%$ and the largest returns to education are $30 \%$. As we shall see below, the estimates never reach or even come close to these two boundary points. Thus, this interval seems to be a reasonable range for searching for the IVQR estimates.

${ }^{6}$ To see the reason, consider the structural model without measurement error, $Q_{\ln \left(w_{i}\right)}\left(\tau \mid X_{i}, S_{i}^{*}\right)=X_{i} \alpha(\tau)+$ $\beta_{1}(\tau) S_{i}^{*}$. And the measurement error equation is similar to the one in Schennach $(2008): S_{i}=S_{i}^{*}+\epsilon_{i}$. The structural model then becomes, $Q_{\ln \left(w_{i}\right)}\left(\tau \mid X_{i}, S_{i}\right)=X_{i} \alpha(\tau)+\beta_{1}(\tau) S_{i}-\beta_{1}(\tau) \epsilon_{i}$. Since $\epsilon$ is not observed, the estimating quantile regression is just (2): $Q_{\ln \left(w_{i}\right)}\left(\tau \mid X_{i}, S_{i}\right)=X_{i} \alpha(\tau)+\beta_{1}(\tau) S_{i}$. Comparing the structural model and the estimating model, we can see that, due to the linearity assumption, the resulting composite error term in the estimating quantile regression consists of only two components, the structural error term (the error term in the original structural model) and $-\beta_{1}(\tau) \epsilon_{i}$; unlike in more general non-separable models, $\epsilon_{i}$ does not depend on the true value of endogenous variable (i.e. true education, $S_{i}^{*}$ ), and, as a result, it does not depend on the IV; the composite error term thus does not depend on the IV (the IV is assumed to be independent with the error term in
} 
assumption useful? The answer is yes. Even though the linearity assumption may be restrictive, Angrist et al. (2006) show that linear quantile regression is still useful, providing a weighted least squares approximation to an unknown and potentially nonlinear conditional quantile regression. ${ }^{7}$

Second, earnings can be measured with errors as well. As noted in Gibson and Kim (2010, p.690), self-reported income can be thought of as a function of true income and random error: $\ln \left(w_{i}\right)^{*}=\theta+\sigma \ln \left(w_{i}\right)+v_{i}$, where $\ln \left(w_{i}\right)^{*}$ is self-reported (mis-measured) earnings and $\ln \left(w_{i}\right)$ true earnings; $v_{i}$ is a pure random (measurement) error. $\theta$ is a constant, $\sigma$ represents the negative correlation between the true values and the measurement error. This expression nests both classical measurement error and mean-reverting error. The classical measurement error $\ln \left(w_{i}\right)^{*}=\ln \left(w_{i}\right)+v_{i}$ is a special case where $\sigma=1$ and $\theta=0$. The mean-reverting measurement error $\ln \left(w_{i}\right)^{*}=\sigma \ln \left(w_{i}\right)$ is a special case where $0<\sigma<1$ and $\theta=0$ and $v_{i}=0$. Both types of the measurement errors can be thought of as an omitted variable in the specification, but they will have different implications for our estimates. In the case of classical measurement error, the error is not correlated with the true earnings and thus not correlated with the variables in the model. As a result, the classical measurement error will only affect the efficiency (instead of the consistency) of the estimates. However, the efficiency is not that big of an issue here. As we shall see below, our coefficients are still precisely estimated. On the other hand, the mean-reverting measurement error is negatively correlated with the true earnings and thus so with the education. Since this type of measurement error can be thought of as an omitted variable, according to the omitted variable formula derived for the condtional quantile regression in Angrist et al. (2006, p.547), the quantile coefficients are biased downward, as in the case of linear regression (the linear case is shown in Bound et al. the structural model). The exogeneity assumption is thus still valid in our case.

${ }^{7}$ Note, also, that even if we are interested in estimating a non-separable model of earnings, the method proposed in Schennach (2008) is not necessarily applicable and of interest in this context. In particular, Schennach (2008) considers only the classical measurement error, and her method may not necessarily address more general types of the endogeneity problem. And the literature generally considers that the endogeneity problem be more important in practice than the measurement error problem (e.g. Lemieux and Card (2001) and Card (1999)). That said, a more systematic investigation of the relative importance of the measurement error bias and the endogeneity bias is still warranted. But the method proposed in Schennach (2008) cannot be readily implemented using the standard QR and IV techniques. A recent paper by Galvao and Montes-Rojas (2009), based on the IVQR approach used here, proposes an instrument variable quantile approach for panel data with measurement errors. However, their method requires panel data, which are generally not available, especially in the Chinese context. We thus leave this exercise to future research. 
(1994) and Gibson and Kim (2010)). The error is proportional to the true earnings and thus to the $X_{i} \alpha(\tau)+\beta_{1}(\tau) S_{i}$. As a result, although the actual bias at each quantile would depend on the true effect of education at the quantile, the overall pattern of the quantile coefficients should not change. $^{8}$

\subsubsection{Summation}

In our analysis, we employ two types of approaches to estimate the rates of returns to education regression and distributional approaches; the former focuses on average effects, whereas the latter looks at the heterogenous effects at different parts of the distribution. In order to isolate the causal effects, we use the instrument variable estimation for both mean (2SLS) and distributional (IVQR) approaches. The IVQR approach is our focus in the paper, as it addresses both the heterogeneity and endogeneity problems.

\section{Data}

The data are obtained from the China Household Income Project (CHIP) 1995 and 2002. ${ }^{9}$ We focus on the urban sample, as household income is generally indivisible in rural areas (Millimet and Wang, 2006). The 1995 and 2002 samples were obtained using a multi-stage methodology, and they are generally considered to be the best publicly available microdata in China. The data have been used widely in the literature; we thus provide limited discussions here. For further details on the data, see e.g. Gustafsson et al. (2008).

The outcome variable of interest is annual wages, measured by the total individual salary (equal to the sum of regular salary, bonuses and subsidies, allowance for temporarily laid off

\footnotetext{
${ }^{8}$ To further investigate the impact of mean-reverting measurement error on our results, we simulate the true earnings using the above formula $\ln \left(w_{i}\right)^{*}=\sigma \ln \left(w_{i}\right)$, in other words, the true earnings $\ln \left(w_{i}\right)=\frac{1}{\sigma} \ln \left(w_{i}\right)^{*}$, for $\sigma=.6, .7, .8, .9$. Given the computational complexity of the IVQR approach, we focus on these values similar to those reported in the literature. For example, Kim and Solon (2005) convert the estimates of measurement error reported in Bound et al. (1994), finding that $\sigma$ ranges from 0.779 and 0.853. As expected, this exercise shows that the quantile coefficients are smaller than the true ones. However, the pattern of the coefficients (and thus the qualitative conclusions) remains unchanged. The results are omitted but available upon request.

${ }^{9}$ The CHIP 1988 data are also available but less comparable to more recent data; the later years are thus our focus in the current analysis.
} 
workers, and other income from the work unit) plus income from private enterprise. Notice that we use nominal wages here without adjusting for inflation, as the dependent variable in estimation is the logarithm of annual wages and the adjusting factor would be absorbed in the intercepts. The primary independent variable of interest is education, measured by years of schooling. Information on weeks and hours worked was not consistently asked across years. We thus focus on annual wage but do assess the robustness of our results using hourly wages (based on information available) below.

Another important measure of human capital - working experience and working experience squared-is also utilized. Note that, while the potential working experience is commonly used in the literature, we are able to utilize actual working experience in our analysis. In China and many other Asian countries, working experience (seniority) is one of the most important criteria for promotion and salary increases (Millimet and Wang (2006)). In addition to schooling and working experience, additional exogenous covariates are also included in estimation. Among these variables are a dummy variable indicating an individual's minority status; and a set of age group dummy variables (aged 16-25, 26-35, 36-45, 46-55, 56-65) that are used to control for cohort effects. The eleven provinces included in the sample are Beijing, Shanxi, Liaoning, Jiangsu, Anhui, Henan, Hubei, Guangdong, Yunnan, Gansu, and Sichuan. The 2002 data sampled the municipality of Chongqing. The legal minimum working age is set at 16 in China. The mandatory retirement age could be extended with Party committee approval, depending on government positions, and the announced maximum age is 65 . So, we restrict the sample to individuals aged 16 to 65 .

Table (1) presents the summary statistics. The first (last) two columns show variable means by gender in 1995 (2002). Relative to men's earnings, women's earnings are smaller in both years. The gap of $\log$ annual wages widened over time, increasing from .234 in 1995 to .25 in 2002 . This result is consistent with the increasing trend in gender gap typically found in the literature (e.g. Zhang et al., 2008). It is also interesting to note that the gap is comparable to the recent estimate of gender gap in the U.S. (e.g. 0.2465 in 1998, Blau and Kahn, 2006). Looking at years of schooling, we observe that men typically have more education and accumulate more working 
experience than do women. This observation holds in both years. These observations also suggest the importance of human capital in wage determination.

\section{Discussions of Validity of Instrument Variable}

As mentioned above, estimating the returns to education is complicated by the potential endogeneity problem. As noted in the literature, searching for a good instrument for education is by no means a trivial task. In order to focus on the heterogeneous earnings effects of education, we borrow a typical IV from the existing literature. While we do not propose our own IV here, we do hope to perform various specification tests to assess the empirical validity of the IV employed within our context in this section.

The IV utilized in our analysis is spousal education. This IV has been utilized both in the Chinese context (e.g. Chen and Hamori, 2009) and in the international context (e.g. Trostel et al., 2002; Arabsheibani and Mussurov, 2007). Recall that for the IV estimates to be meaningful, our instrument, spousal education, has to be correlated with the endogenous variable (own education), but independent of individual's potential wage. We now discuss the evidence concerning each of these requirements in turn.

To assess the former requirement, we first notice that the theoretical relationship between an individual's own education and her spousal education is implied by the literature on positive marital assortative mating (see Becker (1981) for original ideas). The notation of positive assortative mating refers to the fact that individuals tend to marry those with similar characteristics. There has been much empirical evidence supporting positive assortative mating with respect to education (e.g. Mare, 1991; Qian, 1998;). The empirical studies generally find a strong positive correlation between an individual's own education and her spousal education. Moreover, Chen and Hamori (2009) and Chong et al. (2009) confirm the existence of assortative mating effects in the Chinese context. To formally test the positive assortative mating effects using our own data, we provide the results from the first-stage regressions of 2SLS in Table (2) (Panel A). In terms of the first- 
stage results, as expected, spousal education has a positive and statistically significant effect on own education in both 1995 and 2002. In particular, an increase in spousal education by 1 year is associated with an increase in own education by .5 year. Moreover, the relationship is relatively stable over time.

Although encouraging, statistical significance alone is not sufficient to rule out a weak instrument problem. Thus, Panel B in Table (2) presents results from two additional tests assessing the relevance of our instrument: the Kleibergen-Paap rank Wald Statistic and the first-stage Fstatistic for the significance of the instrument. Our instrument fares very well in terms of these tests, implying no weak-IV problem in our context.

The second requirement for a valid instrument is independence; the instrument must be independent of potential wages (conditional on $X$ ). Such dependence could arise from either a direct impact of the instrument on wages (i.e., the instrument belongs in the second-stage), or an indirect effect arising from correlation between the instrument and unobservable determinants of individuals' wages (i.e., the instrument itself is endogenous). One possible source for this dependence is the cross-productivity effect of spousal education. The cross-productivity hypothesis suggests that spousal education may affect an individual's earnings by increasing an individual's human capital (that is not completely captured by one's years of schooling). Another possible source is correlated measurement error. If we expect self-reported education to be measured with errors, not only can both own and spousal education contain errors; they also can be correlated across spouses. Both possibilities imply a positive direct effect of our instrument on individual's wage.

Given these concerns, we undertake a test based on a novel method recently proposed in Conley et al. (Forthcoming). This approach allows us to examine how robust our results are to the presence of general dependence between potential wages and spousal education (caused by either cross-productivity effects or other types of mechanisms). The method is couched in a modified version of the model given in (1). The modification entails permitting spousal education to have a direct impact on individual's wage, regardless of mechanisms through which the instrument affects 
the outcome. Formally, the model is now given by

$$
\begin{aligned}
\ln \left(w_{i}\right) & =\beta_{1} S_{i}+\lambda Z_{i}+\beta_{2} E_{i}+\beta_{3} E_{i}^{2}+\text { Minor }_{i} \beta_{4}+\text { Age }_{i}^{\prime} \beta_{5}+\text { Province }_{i}^{\prime} \beta_{6}+\epsilon_{i} \\
S_{i} & =\pi Z_{i}+\pi_{2} E_{i}+\pi_{3} E_{i}^{2}+\text { Minor }_{i} \pi_{4}+\text { Age }_{i}^{\prime} \pi_{5}+\text { Province }_{i}^{\prime} \pi_{6}+u_{i}
\end{aligned}
$$

Note that the second requirement implies $\lambda=0$. Conley et al. (Forthcoming) seek to construct a valid confidence interval for $\beta_{1}$ even when this requirement fails to hold. Their approach referred to as the Union of Confidence Intervals (UCI) with $\lambda$ support assumption approach assumes that $\lambda \in \Gamma$, where $\Gamma$ is the bounded support of $\lambda$. Given a specific value of $\lambda$ from the support, say $\lambda_{0}$, one can subtract $Z_{i} \lambda_{0}$ from equation (6), yielding

$$
\widetilde{\ln \left(w_{i}\right)}=\ln \left(w_{i}\right)-Z_{i} \lambda_{0}=\beta_{1} S_{i}+\beta_{2} E_{i}+\beta_{3} E_{i}^{2}+\text { Minor }_{i} \beta_{4}+\text { Age }_{i}^{\prime} \beta_{5}+\text { Province }_{i}^{\prime} \beta_{6}+\epsilon_{i} .
$$

Notice that after subtracting $Z_{i} \lambda_{0}, Z_{i}$ is no longer in the Equation (8). That is, $Z_{i}$ is a valid instrument for $S_{i}$ when the outcome is $\widetilde{\ln \left(w_{i}\right)}$. One can thus consistently estimate $\beta_{1}$ via 2SLS using $Z_{i}$ as an instrument and construct a symmetric $(1-\alpha) \%$ confidence interval, $C I_{N}\left(1-\alpha, \lambda_{0}\right)$, based on the asymptotic variance of the 2SLS estimator. However, because the true value is unknown, one can estimate $\lambda$ for all values within the support $\Gamma$ via 2 SLS regressions of $\widetilde{\ln \left(w_{i}\right)}$ on $S_{i}$ and construct the union of the resulting confidence intervals. As long as $\lambda \in \Gamma$, the union will contain the true parameter value of $\beta_{1}$ as $\operatorname{Pr}\left[\beta_{1} \in \underset{\lambda_{0} \in \Gamma}{\cup} C I_{N}\left(1-\alpha, \lambda_{0}\right)\right] \geq(1-\alpha)$ asymptotically. ${ }^{10}$

To implement the UCI approach, we utilize an interval for $\Gamma$ consistent with our discussions above. Specifically, we use a positive support $\Gamma=[0, \delta]$ for different values of $\delta$, consistent with the positive cross-productivity effects of spousal education, as well as other channels that lead to a positive effect of spousal education on individual earnings. ${ }^{11}$

The results representing 90\% confidence intervals are displayed in Figure (1). The upper

\footnotetext{
${ }^{10}$ Since $\operatorname{Pr}\left[\beta_{1} \in C I_{N}\left(1-\alpha, \lambda_{0}\right)\right] \rightarrow(1-\alpha)$ when $\lambda=\lambda_{0}$, it follows that $\operatorname{Pr}\left[\beta_{1} \in \underset{\lambda_{0} \in \Gamma}{\cup} C I_{N}\left(1-\alpha, \lambda_{0}\right)\right] \geq(1-\alpha)$. In practice, we approximate the interval by taking the union of the confidence intervals for grid points in the support $\Gamma$.

${ }^{11}$ We also use a symmetric support centered at zero: $\Gamma=\{-\delta, \delta\}$ for different values of $\delta$. The results, however, do not change and are thus omitted but available from the authors upon request.
} 
(lower) panel shows the 1995 (2002) results; the left (right) column display the results for male (female). The green line is the 2SLS estimates, and two lines surrounding the estimates (one is a solid red line, and the other is a dashed line) are the upper and lower limits of the confidence intervals, respectively. If the lower limits cross the line $(0)$, then our confidence intervals contain zero, suggesting the IV estimates are no longer significant at the $p \leq 0.10$ level. If the lower limit crosses the zero line at the larger value, the result is more robust.

For the male results, the confidence intervals exclude zero at $\lambda=2 \%$ in 1995 and even at $\lambda=4 \%$ in 2002. In other words, even if spousal education had a direct impact on earnings as large as 2\% in 1995 and 4\% in 2002, the qualitative conclusions remain unchanged. For the female results, the confidence intervals exclude zero at $\lambda=3 \%$ in 1995 and even at $\lambda=5.1 \%$ (although not shown) in 2002; that is, our results are robust even when spousal education had a direct impact on earnings as large as 3\% in 1995 and $5.1 \%$ in 2002. In sum, these results suggest that our 2SLS estimates of returns to education are very robust, even to substantial departures from a perfect IV..$^{12}$

To further provide a reference point to interpret our results, we need to know a plausible range of values for direct effects of spousal education. There are only two papers available for this purpose (to the best of our knowledge). Utilizing CHIP 1995 and 2002, Wang (2010) examines the robustness of the causal effects of spousal college education on individuals' earnings and conclude that positive effects of spousal education simply reflect positive assortative matching phenomenon instead of direct effects (e.g. cross-productivity effects); the results hold true for both husbands and

\footnotetext{
${ }^{12}$ Note that the UCI approach cannot be easily extended to the IVQR framework. We adopt an alternative approach to assess this issue. As noted in Koenker and Bassett (2001, p.148), instead of estimating linear conditional quantile regressions, one can estimate binary outcome models for the probability that the dependent variable exceed certain pre-specified values. Therefore, we re-run linear probability models as in (6) by replacing earnings with a binary indicator of earnings above $i$ th percentile, $i=20,30,40,50,60,70,80$. Then, we apply the UCI method to assess the robustness of the IV estimates in these linear probability models. Even though the coefficients themselves are not directly comparable between the IVQR approach and the IV estimation of linear probability models, the comparison of the relative size of the maximum value of $\delta$ (the upper bound of the support $\Gamma$ ) and the original 2SLS estimates would be informative. And indeed this exercise replicates two main features of the UCI results for 2SLS estimations above. First, our results for the linear probability models are generally robust to the values of $\delta$ up to at least half the size of the 2SLS estimate of the direct effect of own education on income percentiles, except in the case of $\tau=0.8$ for females in 1995. Second, our results are robust to a much larger support of $\lambda$ in 2002 than in 1995. These results indicate that our UCI results may be generalized to the distributional level.In the interest of space, these results are omitted but available upon request.
} 
wives at every part of the earnings distribution. The evidence suggests that our IV is exogenous in the Chinese context, suggesting the upper bounds $\delta=0$ for $\Gamma=[0, \delta]$ for both males and females. Chong et al. (2009) examine the cross-productivity effect of spousal education in the Chinese context using a large twins dataset. They find that the cross-productivity effect, if exists, mainly runs from husbands to wives, but not the other way around. Their largest estimate of a direct impact of spousal education on female's earnings is 3.6\% (Table 5, column (1) in Chong et al., 2009). The year when the data used in their analysis was collected is 2002, which should be highly informative for our results in the lower panel. Their estimates imply that our IV is a perfect IV for the male sample, but is potentially problematic for the female sample; their evidence can be thought of as the upper bounds $\delta$ for $\Gamma=[0, \delta]$ ( $\delta=0$ for males, $\delta=0.036$ for females $)$. However, our sensitivity analysis suggests that our IV estimates are robust not only to the range of values suggested by Chong et al. (2009), but also to the range beyond it. The fact that our IV is robust to even a larger range of values of $\lambda$ than reported in the literature suggests that our results are robust even in the presence of other types of dependence through other channels than the cross-productivity channel (e.g. correlated measurement errors). ${ }^{13}$

In addition to the direct evidence on the productivity effect of spousal education, a look into the literature on the direct effect of parental education on earnings may also help us evaluate the robustness of our IV results above. As noted in Chen and Feng (2009), "the Chinese society is traditionally paternalistic", and social network or family connections (guanxi) is generally important in Chinese society (see also, e.g. Bian (1994) and Knight and Yueh (2008)). Moreover,

\footnotetext{
${ }^{13}$ Note that Chong et al. (2009) is the only paper (to the best of our knowledge) that provides a point estimate of the effect of spousal education in the Chinese context. Before more evidence on the same topic is available, this result should be interpreted and used with caution. In the literature review above, we discuss Li et al. (2005) written by three of the four authors of Chong et al. (2009) - that directly looks at the effects of own education based on the same twins data. They find that the returns to own education are roughly 3.6 percent. However, in Chong et al. (2009), the returns to own education are no longer statistically significant; and the point estimates of returns to spousal education are 3.6 percent, which seems to be the same as the returns to own education estimated in Li et al. (2005). This fact suggests that the returns to spousal education may actually capture the effects of own education; and that there does not necessarily exist causal evidence supporting cross-productivity effects of spousal education. That said, we believe that it could still be a useful starting point. For example, the estimate could be regarded as an upper bound of the potential effects of spousal education on productivity, since it may reflect the effect of own education. Our conclusions would thus be even strengthened in this case. More important, given the nature of this exercise, interested readers could always come back to revisit the robustness of these results when more evidence on returns to spousal education is accumulated.
} 
Chen and Feng (2009) note that the practice of jieban - children were entitled to work in the same working unit upon their parents' retirement - was also prevalent in China. If better educated parents have better jobs, this practice may entitle their children to better jobs to start with. As a result, parental education is expected to play an important role in determining their children's labor market outcomes. One may thus expect that, everything else equal, parents have more connections and play a larger role in landing one's first job and increasing one's earnings than one's spouse does. This implies that relative to the effect of spousal education, the direct effect of parental education on one's earnings may be larger, thereby providing an upper bound for the plausible values of the effect of spousal education. On the other hand, even if the effect of parental education is smaller than that of spousal education, the difference should not be too large, given the importance of parental education.

Bearing these in mind, we now turn to the results reported in the literature. Utilizing CHIP 2002, Chen and Feng (2009) report the returns to father's and mother's education are 0.4 percent and 0.3 percent, respectively (Table 2, Column (4) in their paper). These values are most useful for our analysis using CHIP 2002. Using another data set (China Urban Household Supplemental Survey on Education 2007), they find a larger effect of parental education for father's education, 1.1\%. These numbers are comparable to those reported in Liu et al. (2000) for Taiwanese. In that paper, the authors find that father's schooling is more important than mother's schooling; and that a father's university education increase one's wages by $15 \%$ compared to an illiterate father, which is equivalent to roughly $1 \%$ increase in wages for an additional year of father's education. In light of our discussions above, the plausible range of the direct effect of spousal education should be well within $[0,3 \%]$ for men and $[0,5.1 \%]$ for women, as it would be difficult to imagine that it is about $7(\approx 3 \% / 0.4 \%)$ or $13(\approx 5.1 \% / 0.4 \%)$ times larger than that of parental education. In sum, we believe that the UCI results suggest that our 2SLS estimates of returns to education are robust.

While all these discussions do not provide a definite answer to the question of whether our instrument is valid, they do increase our confidence in the identification strategy. We now turn to 
the actual estimates of the returns to education in China.

\section{Results}

\subsection{Baseline Results}

Table (3) reports the baseline results for males and females, respectively. Panels A.1 and B.1 present the ordinary regression results treating language as exogenous; column (1) displays the OLS results and columns (2)-(8) display the ordinary quantile regression results (the effects at the 20th, 30th, 40th, 50th, 60th, 70th, and 80th percentiles). Panels A.2 and B.2 present the IV results treating language as endogenous; column (1) displays the 2SLS results and columns (2)-(8) display the IVQR results (again, the effects at the 20th, 30th, 40th, 50th, 60th, 70th, and 80th percentiles). The comparisons among the results are also visually displayed in Figures (2)-(7).

\subsubsection{Mean Results}

We first discuss the mean results so as to facilitate the comparisons with the existing literature. Examination of the mean results (column (1) in Table (3)) reveals three important findings. First, both OLS and IV results indicate a large, positive impact of schooling on an individual's earnings in 1995 and 2002. Moreover, these estimates are economically and statistically significant (at $p \leq 0.01$ level). The estimated returns to education vary from 3.6 (5.6) percent to 8.8 (11.8) percent for men (women). Second, the comparisons of the OLS and 2SLS estimates imply that the OLS approach, failing to address endogeneity and measurement errors problems, consistently underestimates the returns to education for both men and women. This finding is consistent with the existing literature. For example, Card (1999) surveys the literature on returns to education, concluding that the IV estimates are generally 20-40\% above their OLS counterpart. Such a finding is also confirmed by more recent studies, for example, Trostel et al. (2002). Our own calculations are similar to those in the literature, ranging from $22-46 \%$.

Finally, we observe that the rate of return has dramatically increased over time for both men 
and women, in line with the previous evidence (e.g. Heckman and Li, 2004; Fan et al., 2008). In particular, the estimated return to education for men increased from 4.4 percent in 1995 to 8.8 percent in 2002, a two-fold increase; the estimated returns to education for women increased from 7.3 percent in 1995 to 11.8 percent in 2002, a 62-percent increase. This dramatic increase in the returns to education may reflect two changes accompanying the ongoing economic transition in China. On the one hand, education may have been severely undervalued under China's previous centralized economic system (Fleisher and Wang, 2004). The increase in returns to education may be simply because education is appropriately valued at its market rate during the economic reforms moving toward market-based economy. Moreover, economic transition involves restructuring the whole economic system, which may now become more efficient in utilizing the resources available such as human capital; the increase in returns to education may as well reflect the increase in the productivity. On the other hand, as the transition process deepens, there are growing needs for better educated individuals; the increased demand for highly-educated workers can also attribute to the increase in the return to education (Zhang et al., 2005). Notice, however, that despite a sharp increase in returns to education, the magnitude of those returns to education for men $(8.8$ percent) in China remains smaller than the worldwide average returns to education (roughly 10 percent) reported in Psacharopoulos and Patrinos (2004).

\subsubsection{Distributional Results}

Thus far, we have focused on the effects in the conditional mean. To assess the potential heterogenous effects, we now turn to the distributional analysis.

Mean v.s. Quantile Results Examining the quantile results (columns (2)-(8) in Table (3)), we uncover a large degree of heterogeneity in returns to education, while we continue to find positive returns to education across the whole distribution. For example, among the 1995 ordinary quantile results for women, the difference between the largest estimate (6.6 percent at the 20th percentile) and the smallest estimate (4 percent at the 80th percentile) is as large as 2.6 percent; this 
large difference implies that even though all the individuals benefit from having more education, the gains are dramatically different. The results are in stark contrast to the mean results that assume constant returns to education for everyone, highlighting the importance of employing the distributional approach. To facilitate the comparisons of the mean and quantile results, we also plot two sets of graphs for both men and women in Figures (2) and (3). The connected line represents the quantile estimates at different percentiles, and the solid line represents the mean estimate. The position where the crossing of these two lines occurs informs us how representative the mean results are. That the crossing occurs at the lower tail implies that the mean results overestimate the returns to education for the majority of the population. That the crossing occurs at the extreme upper tail implies that the mean results underestimate the returns to education for the majority of the population. Examination of these figures again confirms that the mean results mask a large amount of interesting information across the distribution. Interestingly, the results imply that the mean results appear to overestimate (underestimate) the returns to education for the majority of the population in 1995 (2002).

Ordinary v.s. IV Quantile Results Figures (4) and (5) plot the comparisons of the ordinary quantile and IVQR results for both men and women, respectively. The left column displays the actual estimates, and the right column displays the difference between ordinary quantile and IVQR estimates. As with the mean results, we find that the ordinary quantile approach treating schooling as exogenous greatly underestimates the true returns to schooling at every percentile. More interestingly, the bias varies across the distribution, across gender, and over time. In particular, the bias at every percentile appears to be larger for women than for men, and it also appears to be larger in 2002 than in 1995. There are, however, no discernible patterns of the estimated bias over the earnings distribution.

IV Quantile Results for both men and women Figure (6) plots the actual IVQR estimates (left column), as well as the differences between the 1995 and 2002 results (right column) for the comparisons of changes over time. Examining the results in the left column, we consistently 
find that the estimated coefficients are larger in the lower tail of the earnings distribution than they are in the upper tail. That is to say, the least earners enjoy larger gains from having an additional year of education than do the highest earners. Moreover, the rates of return appear to monotonically decline as the quantile increases; the only exception is the 2002 IVQR results for men, where the returns to education first increase until the 30th percentile, then steadily decline until the 70th percentile, and finally increase slightly at the 80th percentile. Overall these results still show a declining pattern similar to other samples. The results are of paramount importance for policymaking. Our result suggests that education reduces earnings inequality, providing strong evidence supporting such educational policies aimed at making education affordable and expanding educational opportunity. Notice, also that our IVQR result starkly contrasts with most existing evidence for developed countries. For example, Martins and Pereira (2004) estimate the returns to education for male workers from 16 countries using the quantile regression approach. The authors find that returns to education increase with the quantile, suggesting that schooling actually increases income inequality.

Discussions Following the interpretations common in the prior literature, we interpret the percentile here as the level of individual ability (e.g. Chernozhukov et al., 2007; Arias et al., 2001; Patrinos et al., 2006). Therefore, following the literature (e.g. Mwabu and Schultz, 1996), we interpret this result as the negative relationship between the returns to education and ability. That is, abler individuals receive lower marginal benefits of schooling than do less able individuals, in line with Ashenfelter and Rouse (1998) and recent studies for developing countries (e.g. Patrinos et al., 2006). The questions arise: what can explain the observed pattern of our results, i.e. the negative relationship between the returns to education and ability? And why is it different from the one observed in developed countries?

One possible and straightforward explanation for the discrepancy between our results and the results from the developed countries may be that the ordinary quantile regression approach used in the studies of developed countries does not adequately address the endogeneity problem, thereby 
failing to provide the true picture of the underlying pattern of returns to education. For example, Chernozhukov et al. (2007) utilize the IVQR approach and estimate the returns to education in the U.S.. The authors, using the college proximity as IVs for schooling, find that the return to schooling is $0.175,0.033$, and 0.103 at 25 th, 50 th, and 75 th percentiles, respectively; this result is indeed more or less consistent with our result above and is different from those results using the ordinary quantile regression approach.

However, we believe the most important reasons for the discrepancy lie in the differences in the educational systems, the differences in the stage of economic development, and the differences in the labor market structures between China and developed countries. There are three possible explanations for the observed result. Mwabu and Schultz (1996) offer the first explanation. The authors argue that education and ability are substitutes, which implies the negative relationship between education and ability. The second explanation could be that under-education - situations where workers have fewer skills than required in their jobs - is prevalent in China. In this case, education matters less among high-ability workers, and thus returns to education would be particularly lower in the upper tail of the distribution. These two explanations are related to the distinct features of the education system in China. As noted in Li et al. (2005), the Chinese education system is exam-oriented. Both students in junior high school and those in high school need to take an entrance exam to advance to higher level of institutions. Furthermore, it was not until recently that an entrance exam for junior high school was removed. Moreover, schools and teachers are evaluated based on the performances of their students in these entrance exams. As a result, schools generally "place great emphasis on exam-taking techniques". This type of education generally provides fewer skills than required for jobs, and abler individuals may not necessarily need formal education to acquire the skills provided by it. As a result, compared to developed countries, ability and education is more likely to be substitutes, and under-education is more prevalent in China.

The last explanation is related to the mobility argument in Patrinos et al. (2006). China strictly implements a household registration ( $h u k o u$ ) system that imposes strong restrictions on individual 
migration. ${ }^{14}$ Under the system, as opposed to those abler individuals, the less-able individuals may have fewer means to move. Education may thus be even more important for those less able individuals, as higher levels of schooling may allow them to migrate to better places for better jobs, thereby increasing their earnings. For example, Knight and Yueh (2004) find that education is positively associated with job mobility in urban areas. ${ }^{15}$ This effect can be potentially large across urban areas even within the same province. ${ }^{16}$ Also, college students are allowed to transfer their household registrations to collective household registration of the universities where they are enrolled. Therefore, the larger impact of education in the lower tail of the distribution may be attributed to the added mobility effect of education.

In sum, these distinct features of Chinese education system and labor market may help explain the different patterns of the returns to education between China and developed countries.

IV Quantile Results: 1995 v.s. 2002 While the mean results indicate that average individuals received increased returns to schooling as the economic reforms proceeded, there is no reason one should think everyone would benefit from these reforms. For example, due to the Chinese government's protectionist policies aimed at keeping equity, education of the individuals in the lower tail of the earnings distribution may be consistently overvalued, while that of those in the upper tail may be consistently undervalued. If this is the case, then we may expect that as economic transition deepens and the wages are primarily determined by the market, the returns to education may fall in the lower tail but increase in the upper tail of the earnings distribution. On

\footnotetext{
${ }^{14}$ Interested readers are referred to Zhao (2005) for a detailed review of the household registration system and migration policies in China.

${ }^{15}$ For example, Guangdong province recently started to implement a point-accumulation system for migration that makes the role of education in migration even more explicit. Individuals who earn more than 85 points are immediately eligible to apply for household registration in Guangzhou. The system rewards 4-year college education 80 points but it rewards high school education 20 points; this implies individuals with college education are almost four times more likely to migrate than individuals with high school education. Source: http://baike.csddt. com/TopicView . aspx?topicId=1186.

${ }^{16}$ Take Guangdong, one of the richest provinces in China, as an example. The average annual earnings in the urban areas of Meizhou, one of the relatively poor cities in Guangdong, are 9694 Yuan in 2002 (1171.197 U.S. dollars), while that in Shenzhen, one of the rich cities in Guangdong, is 28087 Yuan (3393.379 U.S. dollars). This implies that moving from Meizhou to Shenzhen can, on average, increases annual earnings by almost $300 \%$. Source: http://stats.meizhou.gov.cn/modules/data/article.php?storyid=208 (Meizhou Bureau of Statistics); http://www.sztj.com/main/xxgk/tjsj/tjgb/gmjjhshfzgb/200302071581.shtml (Shenzhen Bureau of Statistics).
} 
the other hand, as noted in Heckman (2003), as the economic reform deepens and China becomes more integrated into global markets, newer technology that requires better educated workers may be accessed, which in turn increases overall demand for the skilled and educated labor force. This implies that economic transition may lead to increased returns to education in general. The magnitudes of the increased benefits for different people may depend on the size of the increased demand for education in the sectors where these people are. In sum, there is no clear prediction as to the changes of the returns to education at different parts of the earnings distribution over time. The comparisons of the 1995 and 2002 IVQR results are presented in the right column of Figure (6). Surprisingly, we find that the difference between the 2002 and 1995 results is positive everywhere, implying that the returns to education are uniformly larger at every parts of the distribution in 2002 than in 1995. This fact may be consistent with the increasing overall demand for a skilled labor force.

IV Quantile Results: Men v.s. Women Figure (7) plots the comparisons of the IVQR results between men and women. The left column displays the actual IVQR estimates and the right column the differences. Two results stand out. First, in addition to a large degree of within-group heterogeneity above, we also find that there exists a large degree of between-group heterogeneity. In particular, the returns to education are larger for women than for men at every percentile in 1995 and 2002. For example, the difference in the estimated returns to education between women and men at the 60 th percentile is as large as 4.7 percent. This result is consonant with the double effect discussed in Dougherty (2005) - education increases both men's and women's productivity, but it also reduces factors contributing to the gender gap such as discrimination and preferences, an effect pertaining to women only. This result again stresses the potential importance of education in reducing gender gap in addition to within-group inequality. Second, we find that the differences in the results between men and women vary over the earnings distribution, ranging from 1.6 percent to 4.7 percent. This result has a straightforward interpretation following that offered in Dougherty (2005). It suggests that the those factors contributing to the gender gap may 
vary across the whole distribution. Indeed, utilizing CHIP 1988 and 1995, Millimet and Wang (2006) find that discrimination explains at least one-third of the earnings differential in the lower tail of the earnings distribution, but little of the disparity in the upper tail. Taking their evidence in 1995, we may expect that the difference in the returns to education between men and women will be larger in the lower tail of the earnings distribution than in the upper tail. This conjecture is consistent with our 1995 results that show that the largest difference occurs at the 20th percentile whilst the smallest difference occurs at the 80th percentile.

\subsection{Sensitivity Analysis}

We have so far focused on annual wage as our measure of earnings since information on weeks and hours worked is not consistently asked across years. ${ }^{17}$ Because individuals with more education may also be correlated with hours worked, we re-estimate our models using log hourly wages, and the results are presented in Table (A2).

We note that the results, although quantitatively distinct, remain qualitatively unchanged. In the interest of brevity, we simply highlight the main differences. First, the results based on annual wage are in general smaller than those based on hourly wage. Consonant with Li (2003), this result implies that education and hours worked may be negatively correlated, that is, educated individuals work less. Second, the extent of heterogeneity in returns to education is in general larger for the results based on hourly wage than those based on annual wage. The only exception is the 2002 results for females. Third, the finding of monotonically declining returns with respect to percentile is even more strengthened when using hourly wage as the dependent variable.

Another related issue is worth mentioning. The existing studies of labor supply for developed countries note that the female labor force participation (LFP) rates are relatively low, compared to the male LFP rates. As a result, the sample of working women may not be a randomly selected

\footnotetext{
${ }^{17}$ In particular, the CHIP 1995 collects information on average hours worked per day and average days worked per month; the CHIP 2002 collects information on months worked, average days worked per month, and average hours worked per day. Total hours worked per year are equal to total months worked multiplied by average days worked per month and average hours worked per day (assuming 12 months for 1995). And hourly wage used in the analysis is then calculated as the ratio of annual earnings and total hours worked per year.
} 
sample from the underlying female population, and estimation using the selected sample may encounter the selection-bias problem. However, as noted elsewhere, this is less likely to be the case for Chinese women due to the fact that the Chinese government has emphasized the importance of gender equality during its recent history. The existing literature suggests that there is little difference in male versus female LFP rates. For example, Li and Zax (2003) examine the labor supply in China, reporting a LFP rate of $83.4 \%$ and $79.8 \%$ for males and females, respectively. Gustafsson and Li (2000, p. 307) note that "women in China are quite similar to men in performing market work." In addition, Millimet and Wang (2006) find little difference across gender in fullversus part-time work in China. As such, we are not concerned about non-random selection into the labor market in the current analysis. Also, solving the selection-bias problem is not trivial; again, the availability of exogenous IVs is required. The instruments used in the literature are arguably problematic. Moreover, the Heckman-type of sample-selection correction method cannot easily be extended to the current IVQR approach. Notice, however, that if there exists a positive selection into labor force, as suggested in Chen and Hamori (2009), our results can be thought of as the upper bounds on the returns to education.

\section{Conclusion}

In this paper, we estimate the effects of education on the earnings distribution in urban China during the period 1995 to 2002. In order to isolate the causal effects of education on earnings, we exploit the identification strategy based on positive assortative matching phenomena in the marriage market. In particular, we utilize spousal education as our instrument variable, the empirical validity of which is also statistically assessed here. We use recently developed instrument variable quantile regression approach to assess the educational effects across the whole earnings distribution. Our results show that, while returns to education are positive everywhere, there exists a large degree of heterogeneity in returns to education across the earnings distribution, as well as across gender. In particular, gains are more pronounced for individuals in the lower tail of 
the earnings distribution than for those in the upper tail, and they are uniformly larger for women than for men across the whole distribution. Moreover, economic returns to education increase over time across the whole distribution. Our results strongly support the view that education can promote individual well-being as well as equality in society.

There are several ways in which our research can be extended. First, due to computational complexity of the IVQR approach, we focus on the heterogeneity across the earnings distribution for both men and women. However, there could still be heterogeneous effects across different groups, regions, and sectors. For example, there may be larger demand for skilled workers in more developed areas such as costal provinces than those less developed provinces, leading to larger returns to education in more developed areas. On the other hand, if the added mobility effects are present, then there may be larger returns to education in less developed areas. Also, the government has a larger control over wages in state-owned sectors than in other sectors, and wages in state-owned sectors are less likely to reflect the underlying productivity of workers than in more privatized sectors. As such, we may expect returns to educations to be less volatile in state-owned sectors than in privatized sectors. Second, while we argue that selection bias due to lower female labor force participation is less of an issue in China, it would still be of great interest to assess how robust our results are to accounting for selection bias in our estimation should a plausibly valid instrument be available. Finally, while we propose several explanations for the large degree of heterogeneity in returns to education uncovered, understanding which explanation matters more should be a goal of future empirical research. 


\section{References}

Angrist, J.D., V. Chernozhukov, and I. Fernandez-Val. 2006. "Quantile Regression under Misspecification, with an Application to the U.S. Wage Structure." Econometrica 74:539-563.

Arabsheibani, G.R. and A. Mussurov. 2007. "Returns to Schooing in Kazakhstan." Economics of Transition 15:341-364.

Arias, O., K. F. Hallock, and W. Sosa-Escudero. 2001. "Individual heterogeneity in the returns to schooling: Instrumental variables quantile regression using twins data." Empirical Economics $26: 7-40$.

Ashenfelter, O. and C. Rouse. 1998. "Income, Schooling, and Ability: Evidence from a New Sample Identical Twins." Quarterly Journal of Economics 113:253-284.

Becker, G.S. 1981. A Treatise on the Family. Cambridge: Harvard University Press.

Bian, Y. 1994. "Guanxi and the Allocation of Urban Jobs in China." China Quarterly 140:971-999.

Blau, F.D. and L.M. Kahn. 2006. "The U.S. gender pay gap in the 1990s: slowing convergence." Industrial and Labor Relations Review 60:45-66.

Bound, J., C. Brown, G.J. Duncan, and W.L. Rodgers. 1994. "Evidence on the Validity of CrossSectional and Longitudinal Labor Market Data." Journal of Labor Economics 12:345-368.

Bound, J., D. A. Jaeger, and R. M. Baker. 1995. "Problems with Instrumental Variables Estimation When the Correlation Between the Instruments and the Endogenous Explanatory Variable is Weak." Journal of the American Statistical Association, 90:443-450.

Brandt, L. and T.G. Rawski. 2008. China's Great Economic Transformation, chapter China's Great Economic Transformation. Cambridge University Press.

Card, D. 1999. Handbook of Labor Economics, volume 3, chapter The causal effect of education on earnings. Amsterdam: North Holland. 
Chen, G. and Shigeyuki Hamori. 2009. "Economic returns to schooling in urban China: OLS and the instrumental variables approach." China Economic Review 20:143-152.

Chen, Y. and S. Feng. 2009. "Parental Education and Wages: Evidence from China." IZA Discussion Paper No. 4218 .

Chernozhukov, V. and C. Hansen. 2008. "Instrumental Variable Quantile Regression: A Robust Inference Approach." Journal of Econometrics 142:379-398.

Chernozhukov, V., C. Hansen, and M. Jansson. 2007. "Inference approaches for instrumental variable quantile regression." Economics Letters 95:272-277.

Chong, H., H. Li, P.W. Liu, and J. Zhang. 2009. "Why Does Spousal Education Matter for Earnings? Assortative Mating and Cross-productivity." Journal of Labor Economics 27:633652.

Conley, T.G., C. Hansen, and P.E. Rossi. Forthcoming. "Plausibly Exogenous." Review of Economics and Statistics .

Dougherty, C. 2005. "Why Are the Returns to Schooling Higher for Women than for Men?" Journal of Human Resources 40:969-988.

Fan, M., Z. Fan, and X. Yu. 2008. "Returns to College Education in China." In 2008 International Symposium on Intelligent Information Technology Application Workshops, pp. 971-974.

Fleisher, B.M., Y. Hu, and H. Li. forthcoming. "Economic Transition, Higher Education and Worker Productivity in China." Journal of Development Economics .

Fleisher, B.M., K. Sabirianova, and X. Wang. 2005. "Returns to skills and the speed of reforms: Evidence from Central and Eastern Europe, China, and Russia." Journal of Comparative Economics 33:351-370. 
Fleisher, B.M. and X. Wang. 2004. "Skill Differentials, Return to Schooling, and Market Segmentation in a Transition Economy: The Case of Mainland China." Journal of Development Economics 73:715-728.

Galvao, A.F. and G.V. Montes-Rojas. 2009. "Instrumental Variables Quantile Regression for Panel Data with Measurement Errors." City University Economics Discussion Papers 0906.

Gibson, J. and B. Kim. 2010. "Non-Classical Measurement Error in Long-Term Retrospective Recall Surveys." Oxford Bulletin of Economics and Statistics 72:687-695.

Giles, J., A. Park, and J. Zhang. 2004. "The Great Proletarian Cultural Revolution, Discruption to Education, and Returns to Schooling in Urban China." Working Paper, Department of Economics, University of Michigan .

Gustafsson, B. and S. Li. 2000. "Economic Transformation and the Gender EArnings Gap in Urban China." Journal of Population Economics 13:305-329.

Gustafsson, B., S. Li, and T. Sicular. 2008. Inequality and Public Policy in China. Cambridge, MA: Cambridge University Press.

Harmon, C., V. Hogan, and I. Walker. 2003. "Dispersion in the Economic Return to Schooling." Labour Economics 10:205-214.

Heckman, J.J. 2003. "China's Investment in Human Capital." Economic Development and Cultural Change 51:795-804.

Heckman, J.J. and X. Li. 2004. "Selection bias, comparative advantage and heterogeneous returns to education: evidence from China in 2000." Pacific Economic Review 9:155-171.

Heckman, J.J., L. Lochner, and P. Todd. 2008. "Earnings Functions and Rates of Return." Journal of Human Capital 2:1-31.

Henderson, D.J., S.W. Polachek, and L. Wang. Forthcoming. "Heterogeneity in Schooling Rates of Return." Economics of Education Review . 
Kanbur, R. and X. Zhang. 2005. "Fifty Years of Regional Inequality in China: A Journey through Central Planning, Reform, and Openness." Review of Development Economics 9:87-106.

Kim, B. and G. Solon. 2005. "Implications of Mean-Reverting Measurement Error for Longitudinal Studies of Wages and Employment." Review of Economics and Statistics 87:193-196.

Knight, J. and L. Yueh. 2004. "Job Mobility of Residents and Migrants in Urban China." Journal of Comparative Economics 32:637-660.

Knight, J. and L. Yueh. 2008. "The Role of Social Capital in the Labour Market in China." Economics of Transition 16:389-414.

Koenker, R. 2005. Quantile Regression. Cambridge University Press.

Koenker, R. and G. S. Bassett. 1978. "Regression Quantiles." Econometrica 46:33-50.

Koenker, R. and G. S. Bassett. 2001. "Quantile Regression." Journal of Economic Perspectives $15: 143-156$.

Koop, G. and J. Tobias. 2004. "Learning About Heterogeneity in Returns to Schooling." Journal of Applied Econometrics 19:827-849.

Lemieux, T. and D. Card. 2001. "Education, Earnings, and the 'Canadian G.I. Bill'." Canadian Journal of Economics 34:313-344.

Li, H. 2003. "Economic Transition and Returns to Education in China." Economics of Education Review 22:317-328.

Li, H., P.W. Liu, N. Ma, and J. Zhang. 2005. "Does Education Pay in Urban China? Estimating Returns to Education Using Twins." CUHK Discussion Papers \# 00013.

Li, H. and Y. Luo. 2004. "Reporting Errors, Ability Heterogeneity, and Returns to Schooling in China." Pacific Economic Review 9:191-207. 
Li, H. and J. Zax. 2003. "Labor Supply in Urban China." Journal of Comparative Economics $31: 795-817$.

Liu, J., J¿Ki Hammitt, and C.J. Lin. 2000. "Family Background and Returns to Schooling in Taiwan." Economics of Education Review 19:113-125.

Mare, R. 1991. "Five Decades of Educational Assortative Mating." American Sociological Review $56: 15-32$.

Martins, P.S. and P.T. Pereira. 2004. "Does Education Reduce Wage Inequality? Quantile Regression Evidence From 16 Countries." Labour Economics 11:355-371.

Millimet, D.L. and L. Wang. 2006. "A Distributional Analysis of the Gender Earnings Gap in Urban China." B.E. Journal of Economic Analysis 8 Policy (Contributions) 5:Article 5.

Mwabu, G. and T.P. Schultz. 1996. "Education Returns Across Quantiles of the Wage Function: Alternative Explanations for Returns to Education by Race in South Africa." American Economic Review 86:335-339.

Patrinos, H.A., C. Ridao-Cano, and C. Sakellariou. 2006. "Estimating the Returns to Education: Accounting for Heteroneity in Ability." World Bank Policy Research Working Paper 4040 .

Polachek, S.W. 2008. "Earnings Over the Lifecycle: The Mincer Earnings Function and Its Applications." Foundations and Trends in Microeconomics 4:165-272.

Psacharopoulos, G. and H.A. Patrinos. 2004. "Returns to Investiment in Education: A Further Update." Education Economics 12:111-134.

Qian, Z. 1998. "Changes in Assortative Mating: The Impact of Age and Education." Demography 35:279-292.

Schennach, S.M. 2008. "Quantile Regression with Mismeasured Covariates." Econometric Theory 24:1010-1043. 
Staiger, D. and J. H. Stock. 1997. "Instrumental Variables Regression with Weak Instruments." Econometrica 65:557-586.

Trostel, P., I. Walker, and P. Woolley. 2002. "Estimates of the economic return to schooling for 28 countries." Labour Economics 9:1-16.

Wang, L. 2010. "Does Spousal Education Matter for Earnings?" Unpublished Manuscript .

Wang, X., B.M. Fleisher, H. Li, and S. Li. 2009. "Access to Higher Education and Inequality: The Chinese Experiment." Unpublished Manuscrpit .

Yang, D.T., V. Chen, and R. Monarch. 2009. "Rising Wages: Has China Lost Its Global Labor Advantage?" Unpublished Manuscript .

Zhang, J., J. Han, P.W. Liu, and Y. Zhao. 2008. "Trends in the Gender Earnings Differential in Urban China, 1988-2004." Industrial \&f Labor Relations Review 61:Article 5.

Zhang, J., Y. Zhao, A. Park, and X. Song. 2005. "Economic returns to schooling in urban China, 1988 to 2001." Journal of Comparative Economics 33:730-752.

Zhao, Z. 2005. "Migration, Labor Market Flexibility, and Wage Determination in China: A Review." The Developing Economics XLIII:285-312. 
Table 1: Summary Statistics

\begin{tabular}{|c|c|c|c|c|}
\hline \multirow[t]{2}{*}{ Variable } & \multicolumn{2}{|c|}{1995} & \multicolumn{2}{|c|}{2002} \\
\hline & $\begin{array}{l}\text { Male } \\
(1)\end{array}$ & $\begin{array}{c}\text { Female } \\
(2)\end{array}$ & $\begin{array}{c}\text { Male } \\
(3)\end{array}$ & $\begin{array}{c}\text { Female } \\
(4)\end{array}$ \\
\hline \multicolumn{5}{|l|}{ Dependent Variable } \\
\hline Log Annual Wages & $\begin{array}{c}8.666 \\
(0.518)\end{array}$ & $\begin{array}{c}8.432 \\
(0.633)\end{array}$ & $\begin{array}{c}9.362 \\
(0.599)\end{array}$ & $\begin{array}{c}9.112 \\
(0.643)\end{array}$ \\
\hline Log Hourly Wages & $\begin{array}{c}2.576 \\
(0.537)\end{array}$ & $\begin{array}{c}2.409 \\
(0.583)\end{array}$ & $\begin{array}{c}1.673 \\
(0.671)\end{array}$ & $\begin{array}{c}1.462 \\
(0.727)\end{array}$ \\
\hline \multicolumn{5}{|l|}{ Independent Variable } \\
\hline Years of Schooling & $\begin{array}{l}11.083 \\
(3.045)\end{array}$ & $\begin{array}{l}10.292 \\
(2.849)\end{array}$ & $\begin{array}{l}11.322 \\
(3.093)\end{array}$ & $\begin{array}{l}11.163 \\
(2.886)\end{array}$ \\
\hline Spouse's Years of Schooling & $\begin{array}{l}10.042 \\
(2.97)\end{array}$ & $\begin{array}{l}11.089 \\
(3.003)\end{array}$ & $\begin{array}{c}10.6 \\
(3.034)\end{array}$ & $\begin{array}{l}11.534 \\
(3.105)\end{array}$ \\
\hline Minority $($ Yes $=1)$ & $\begin{array}{c}0.042 \\
(0.2)\end{array}$ & $\begin{array}{c}0.044 \\
(0.205)\end{array}$ & $\begin{array}{c}0.038 \\
(0.191)\end{array}$ & $\begin{array}{c}0.04 \\
(0.195)\end{array}$ \\
\hline Experience & $\begin{array}{l}23.575 \\
(8.671)\end{array}$ & $\begin{array}{l}19.815 \\
(7.522)\end{array}$ & $\begin{array}{l}24.025 \\
(8.405)\end{array}$ & $\begin{array}{l}20.207 \\
(7.947)\end{array}$ \\
\hline Experience Squared & $\begin{array}{c}630.932 \\
(423.742)\end{array}$ & $\begin{array}{c}449.208 \\
(303.203)\end{array}$ & $\begin{array}{c}647.831 \\
(393.781)\end{array}$ & $\begin{array}{c}471.468 \\
(318.927)\end{array}$ \\
\hline Age $16-25$ & $\begin{array}{c}0.006 \\
(0.075)\end{array}$ & $\begin{array}{c}0.018 \\
(0.134)\end{array}$ & $\begin{array}{c}0.001 \\
(0.039)\end{array}$ & $\begin{array}{c}0.005 \\
(0.072)\end{array}$ \\
\hline Age $26-35$ & $\begin{array}{c}0.211 \\
(0.408)\end{array}$ & $\begin{array}{c}0.286 \\
(0.452)\end{array}$ & $\begin{array}{c}0.147 \\
(0.354)\end{array}$ & $\begin{array}{c}0.236 \\
(0.425)\end{array}$ \\
\hline Age $36-45$ & $\begin{array}{c}0.428 \\
(0.495)\end{array}$ & $\begin{array}{c}0.503 \\
(0.5)\end{array}$ & $\begin{array}{c}0.393 \\
(0.488)\end{array}$ & $\begin{array}{c}0.478 \\
(0.5)\end{array}$ \\
\hline Age $46-55$ & $\begin{array}{c}0.267 \\
(0.442)\end{array}$ & $\begin{array}{c}0.183 \\
(0.387)\end{array}$ & $\begin{array}{c}0.394 \\
(0.489)\end{array}$ & $\begin{array}{c}0.267 \\
(0.442)\end{array}$ \\
\hline Age $56-65$ & $\begin{array}{c}0.087 \\
(0.282)\end{array}$ & $\begin{array}{c}0.01 \\
(0.097)\end{array}$ & $\begin{array}{c}0.066 \\
(0.247)\end{array}$ & $\begin{array}{c}0.013 \\
(0.115)\end{array}$ \\
\hline
\end{tabular}

${ }^{1}$ Notes: Standard deviations in parentheses. Samples are as follows: 1995 and 2002 China Household Income Project (CHIP). Provincial dummies are also included. 


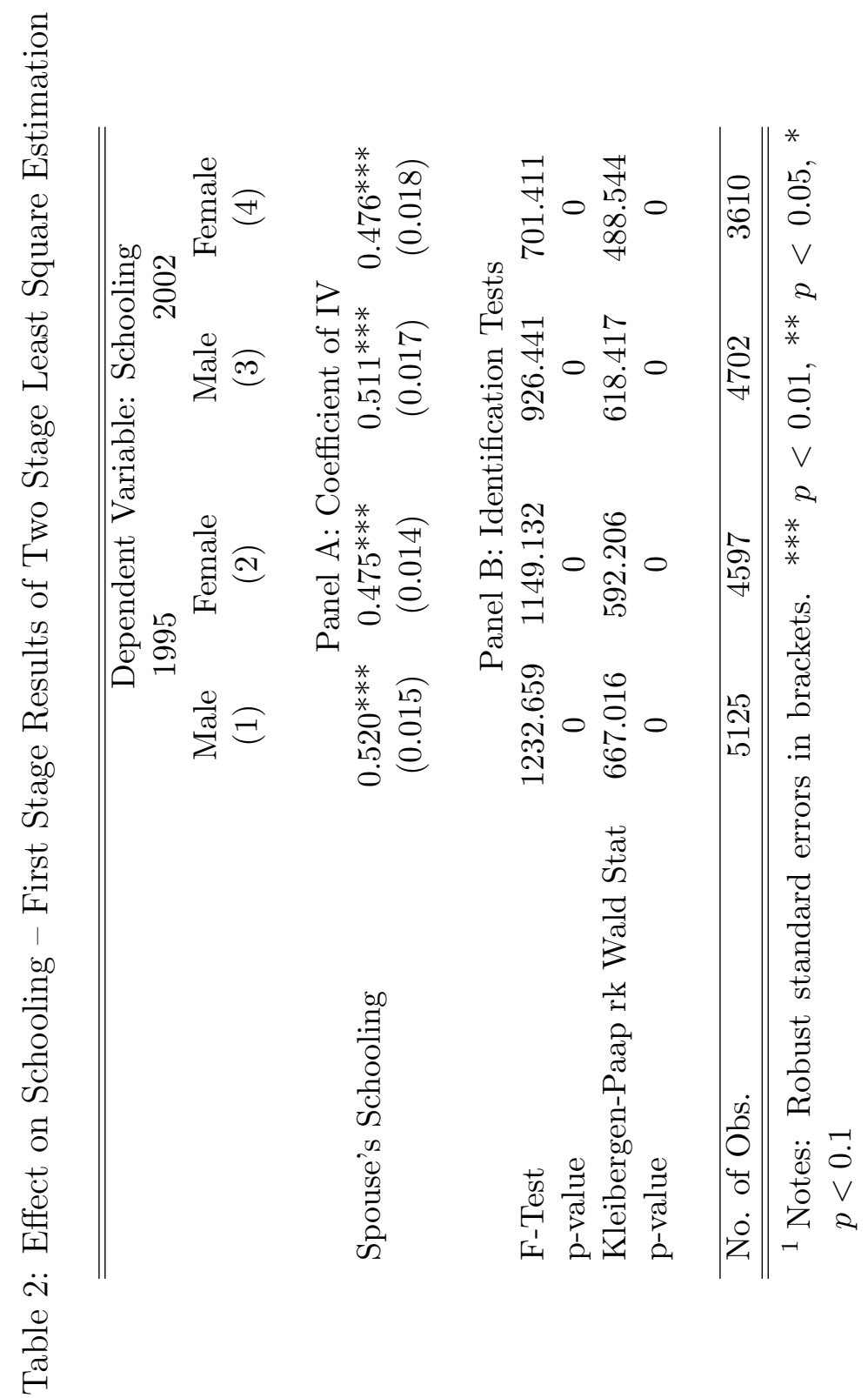


Table 3: Baseline Results

\begin{tabular}{|c|c|c|c|c|c|c|c|c|}
\hline Year & $\begin{array}{l}\text { Mean } \\
(1)\end{array}$ & $\begin{array}{c}\tau=.2 \\
(2)\end{array}$ & $\begin{array}{c}\tau=.3 \\
(3)\end{array}$ & $\begin{array}{c}\tau=.4 \\
(4)\end{array}$ & $\begin{array}{c}\tau=.5 \\
(5)\end{array}$ & $\begin{array}{c}\tau=.6 \\
(6)\end{array}$ & $\begin{array}{c}\tau=.7 \\
(7)\end{array}$ & $\begin{array}{c}\tau=.8 \\
(8)\end{array}$ \\
\hline \multicolumn{9}{|c|}{ Panel A: Male Sample } \\
\hline \multicolumn{9}{|c|}{ Panel A.1: Ordinary Regressions } \\
\hline 1995 & $\begin{array}{c}0.036^{* * *} \\
(0.002)\end{array}$ & $\begin{array}{c}0.043^{* * *} \\
(0.003)\end{array}$ & $\begin{array}{c}0.038^{* * *} \\
(0.002)\end{array}$ & $\begin{array}{c}0.034^{* * *} \\
(0.002)\end{array}$ & $\begin{array}{c}0.031^{* * *} \\
(0.002)\end{array}$ & $\begin{array}{c}0.029 * * * \\
(0.002)\end{array}$ & $\begin{array}{c}0.024^{* * *} \\
(0.002)\end{array}$ & $\begin{array}{c}0.019 * * * \\
(0.002)\end{array}$ \\
\hline 2002 & $\begin{array}{c}0.066^{* * *} \\
(0.003)\end{array}$ & $\begin{array}{c}0.076^{* * *} \\
(0.004)\end{array}$ & $\begin{array}{c}0.073^{* * *} \\
(0.003)\end{array}$ & $\begin{array}{c}0.072^{* * *} \\
(0.003)\end{array}$ & $\begin{array}{c}0.069 * * * \\
(0.003)\end{array}$ & $\begin{array}{c}0.066^{* * *} \\
(0.002)\end{array}$ & $\begin{array}{c}0.065^{* * *} \\
(0.003)\end{array}$ & $\begin{array}{c}0.06 * * * \\
(0.003)\end{array}$ \\
\hline \multicolumn{9}{|c|}{ Panel A.1: IV Regressions } \\
\hline 1995 & $\begin{array}{c}0.044^{* * *} \\
(0.005)\end{array}$ & $\begin{array}{c}0.051^{* * *} \\
(0.006)\end{array}$ & $\begin{array}{c}0.052^{* * *} \\
(0.005)\end{array}$ & $\begin{array}{c}0.047^{* * *} \\
(0.005)\end{array}$ & $\begin{array}{c}0.044^{* * *} \\
(0.005)\end{array}$ & $\begin{array}{c}0.038^{* * *} \\
(0.005)\end{array}$ & $\begin{array}{c}0.033^{* * *} \\
(0.005)\end{array}$ & $\begin{array}{c}0.031^{* * *} \\
(0.005)\end{array}$ \\
\hline 2002 & $\begin{array}{c}0.088^{* * *} \\
(0.005)\end{array}$ & $\begin{array}{c}0.095^{* * *} \\
(0.008)\end{array}$ & $\begin{array}{c}0.102^{* * *} \\
(0.007)\end{array}$ & $\begin{array}{c}0.103^{* * *} \\
(0.007)\end{array}$ & $\begin{array}{c}0.089^{* * *} \\
(0.006)\end{array}$ & $\begin{array}{c}0.081^{* * *} \\
(0.006)\end{array}$ & $\begin{array}{c}0.08^{* * *} \\
(0.006)\end{array}$ & $\begin{array}{c}0.087^{* * *} \\
(0.006)\end{array}$ \\
\hline \multicolumn{9}{|c|}{ Panel B: Female Sample } \\
\hline \multicolumn{9}{|c|}{ Panel B.1: Ordinary Regressions } \\
\hline 1995 & $\begin{array}{c}0.056^{* * *} \\
(0.003)\end{array}$ & $\begin{array}{c}0.066^{* * *} \\
(0.004)\end{array}$ & $\begin{array}{c}0.057^{* * *} \\
(0.003)\end{array}$ & $\begin{array}{c}0.054^{* * *} \\
(0.003)\end{array}$ & $\begin{array}{c}0.049 * * * \\
(0.002)\end{array}$ & $\begin{array}{c}0.043^{* * *} \\
(0.002)\end{array}$ & $\begin{array}{c}0.041^{* * *} \\
(0.002)\end{array}$ & $\begin{array}{c}0.04^{* * *} \\
(0.002)\end{array}$ \\
\hline 2002 & $\begin{array}{c}0.081^{* * *} \\
(0.003)\end{array}$ & $\begin{array}{c}0.087^{* * *} \\
(0.004)\end{array}$ & $\begin{array}{c}0.085^{* * *} \\
(0.004)\end{array}$ & $\begin{array}{c}0.083^{* * *} \\
(0.004)\end{array}$ & $\begin{array}{c}0.084^{* * *} \\
(0.003)\end{array}$ & $\begin{array}{c}0.085^{* * *} \\
(0.003)\end{array}$ & $\begin{array}{c}0.08 * * * \\
(0.003)\end{array}$ & $\begin{array}{c}0.074^{* * *} * \\
(0.004)\end{array}$ \\
\hline \multicolumn{9}{|c|}{ Panel B.2: IV Regressions } \\
\hline 1995 & $\begin{array}{c}0.073^{* * *} \\
(0.006)\end{array}$ & $\begin{array}{c}0.083^{* * *} \\
(0.007)\end{array}$ & $\begin{array}{c}0.075^{* * *} \\
(0.006)\end{array}$ & $\begin{array}{c}0.071^{* * *} \\
(0.006)\end{array}$ & $\begin{array}{c}0.066^{* * *} \\
(0.006)\end{array}$ & $\begin{array}{c}0.061^{* * *} \\
(0.006)\end{array}$ & $\begin{array}{c}0.057^{* * *} \\
(0.006)\end{array}$ & $\begin{array}{c}0.049 * * * \\
(0.006)\end{array}$ \\
\hline 2002 & $\begin{array}{c}0.118^{* * *} \\
(0.007)\end{array}$ & $\begin{array}{c}0.134^{* * *} \\
(0.01)\end{array}$ & $\begin{array}{c}0.128^{* * *} \\
(0.009)\end{array}$ & $\begin{array}{c}0.131^{* * *} \\
(0.009)\end{array}$ & $\begin{array}{c}0.128^{* * *} \\
(0.009)\end{array}$ & $\begin{array}{c}0.128^{* * *} \\
(0.009)\end{array}$ & $\begin{array}{c}0.118^{* * *} \\
(0.008)\end{array}$ & $\begin{array}{c}0.103^{* * *} \\
(0.008)\end{array}$ \\
\hline
\end{tabular}

${ }^{1}$ Notes: Robust standard errors in brackets. ${ }^{* * *} p<0.01,{ }^{* *} p<0.05,{ }^{*}$ 


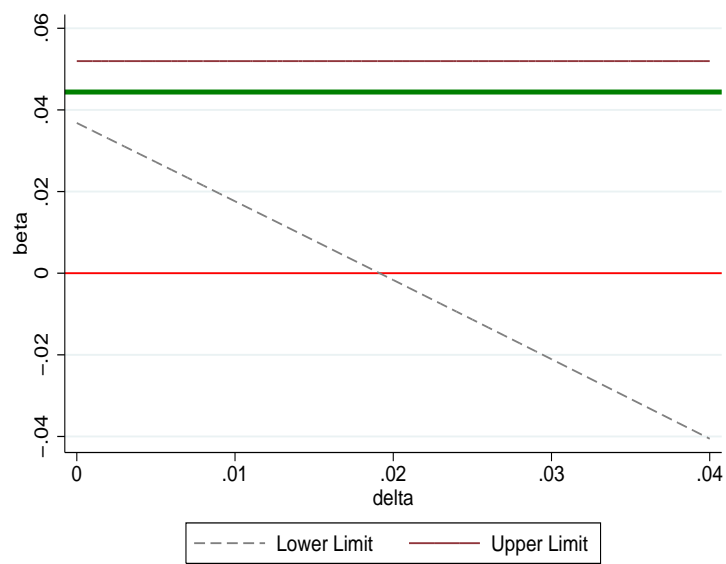

Note: Solid green line is TSLS Estimate

(a) Male

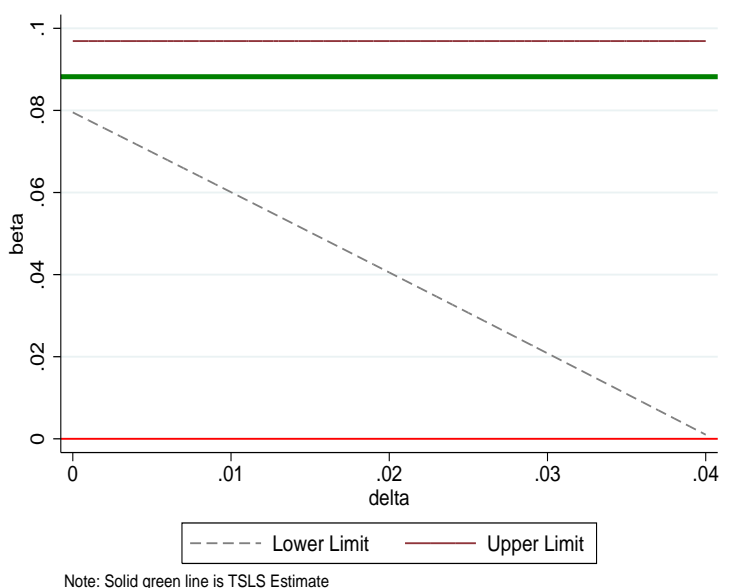

(c) Male

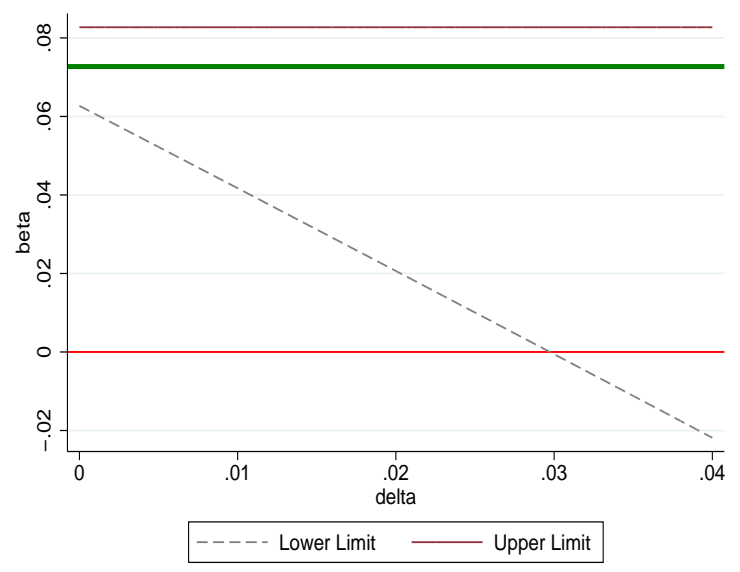

Note: Solid green line is TSLS Estimate

(b) Female

1995

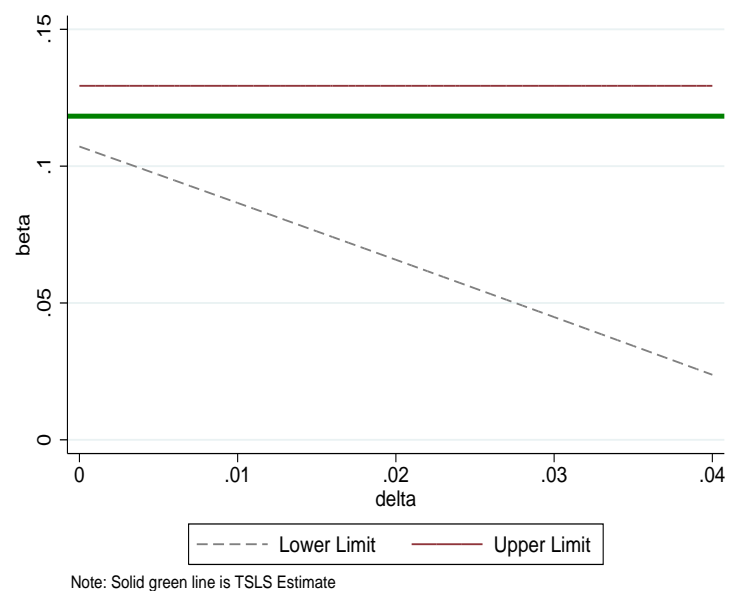

(d) Female

2002

Figure 1: Sensitivity Analysis of Instrument Variable 


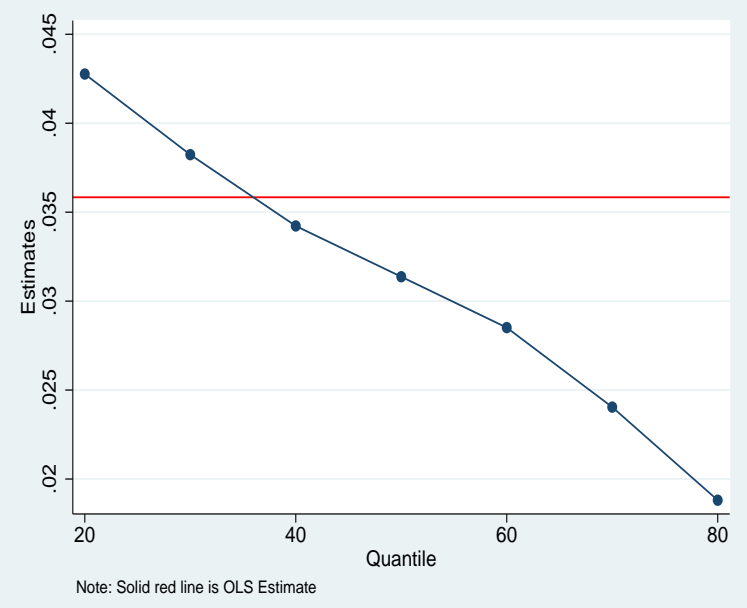

(a) 1995

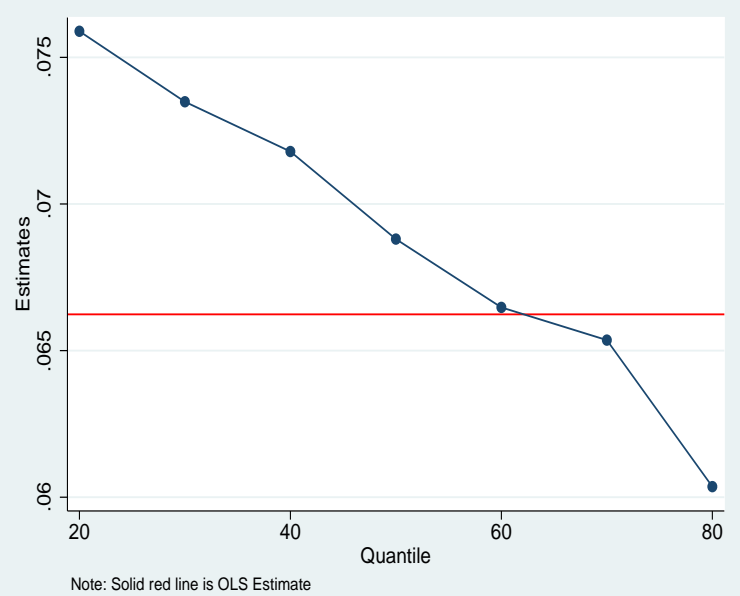

(b) 2002

OLS v.s. QREG

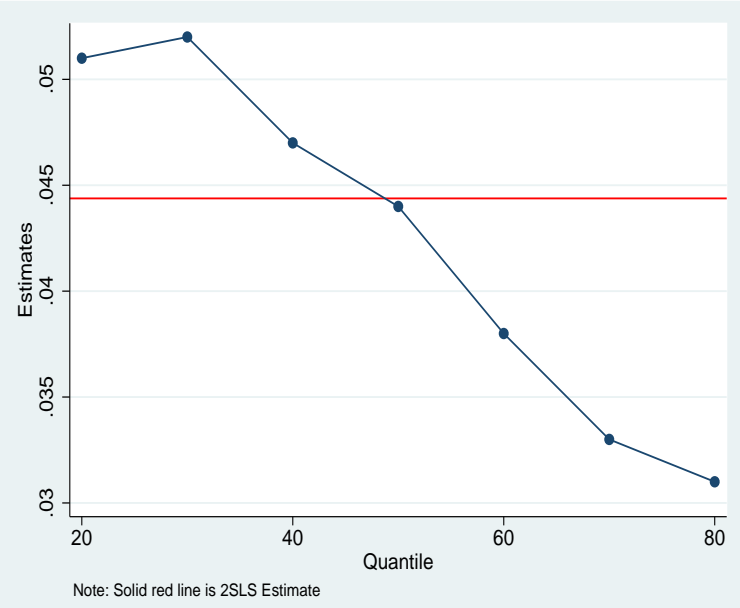

(c) 1995

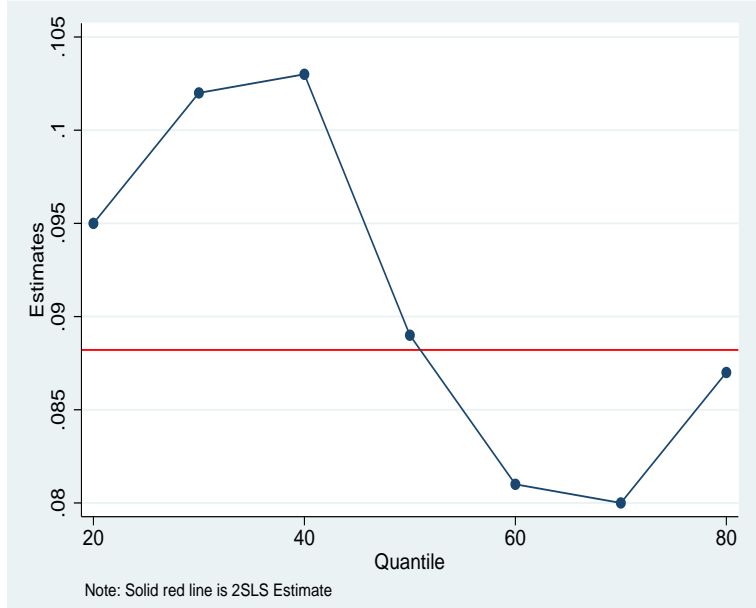

(d) 2002

IV v.s. IVQREG

Figure 2: Comparison between Mean and Quantile Results (Male Sample) 


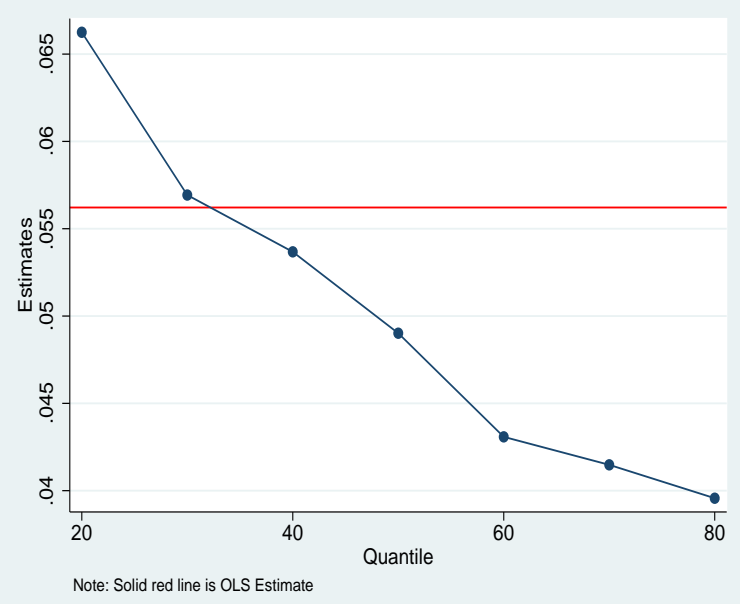

(a) 1995

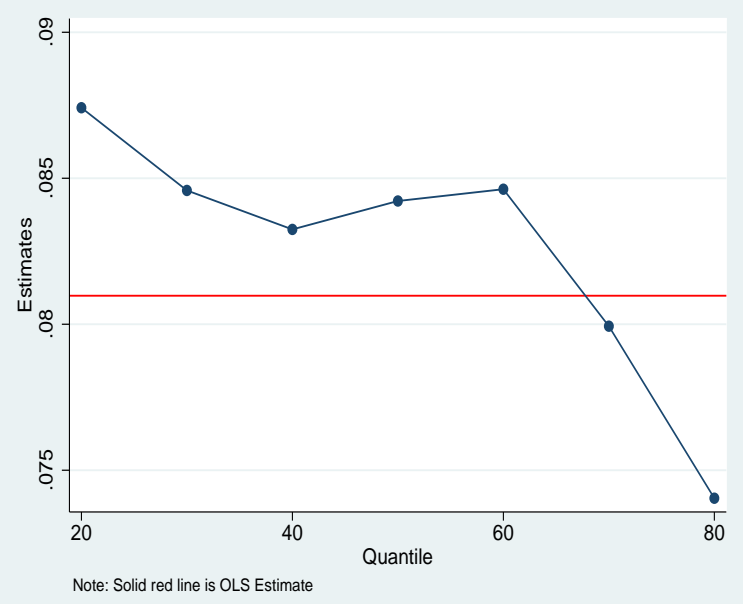

(b) 2002

OLS v.s. QREG

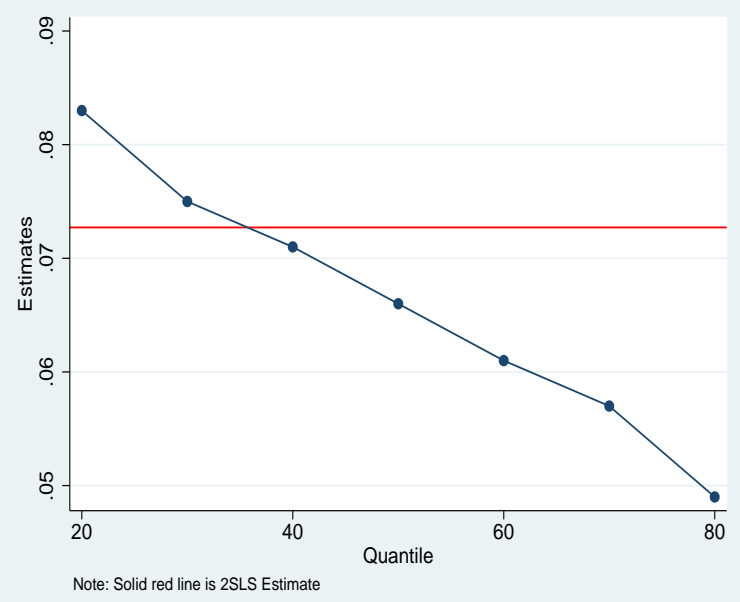

(c) 1995

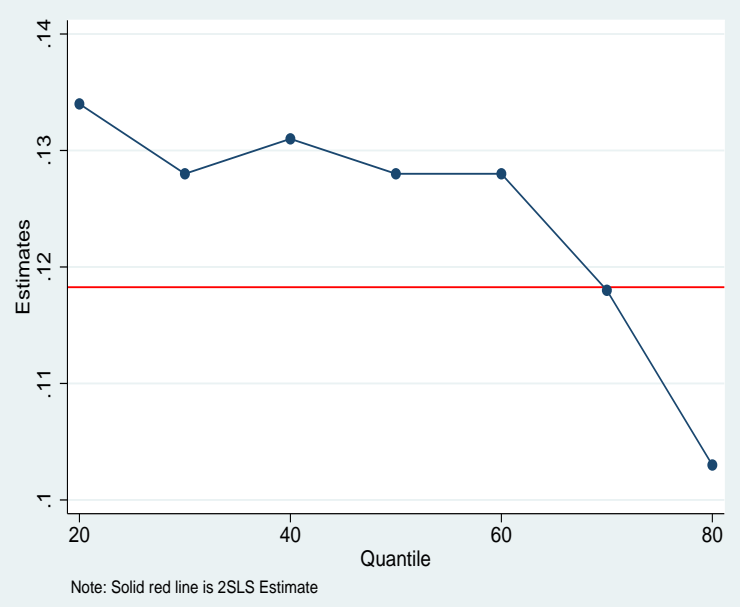

(d) 2002

IV v.s. IVQREG

Figure 3: Comparison between Mean and Quantile Results (Female Sample) 


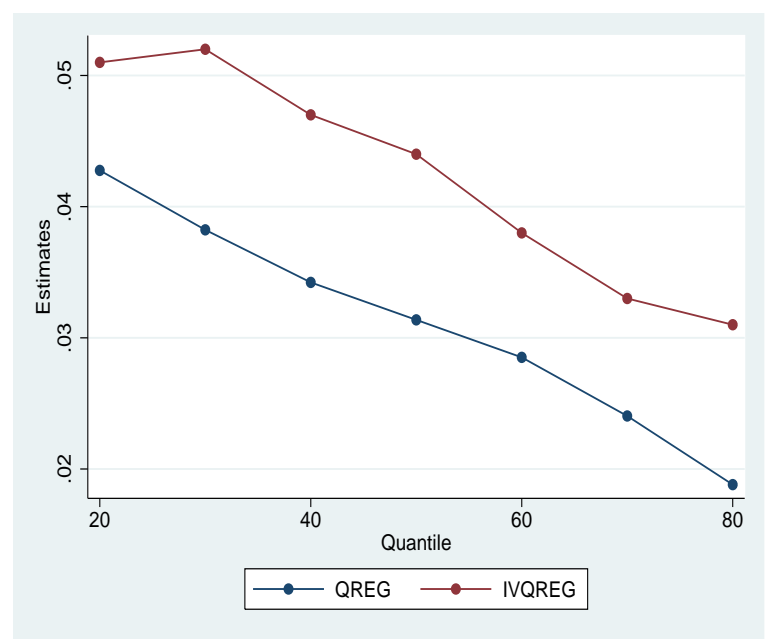

(a) Estimates

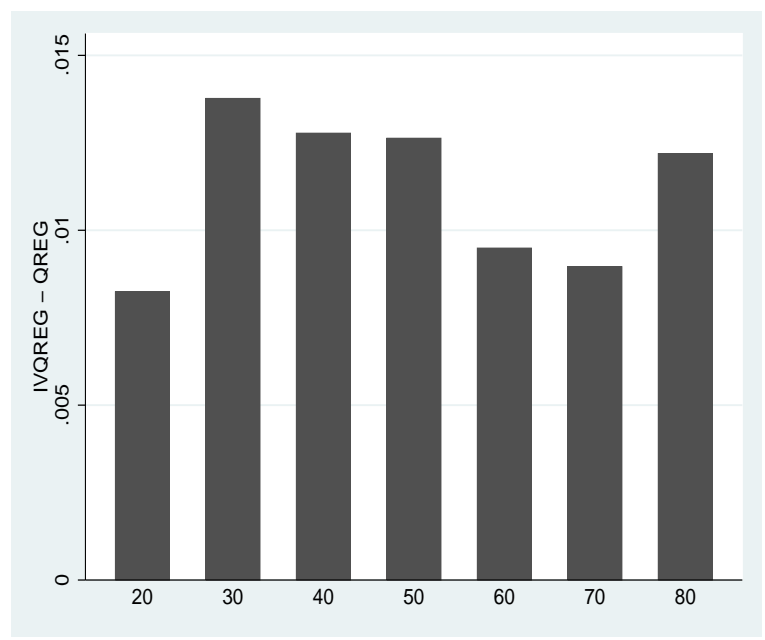

(b) Differences

Ordinary v.s. IV Quantile (1995)

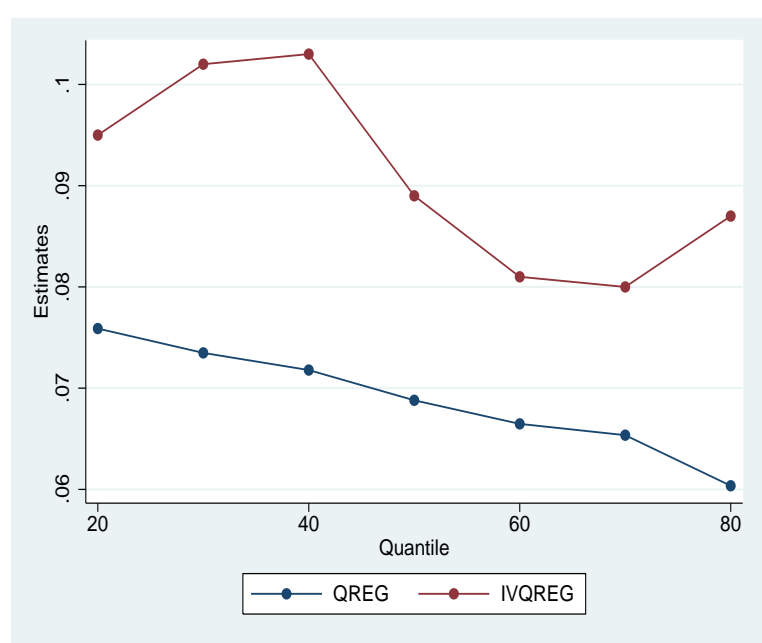

(c) Estimates

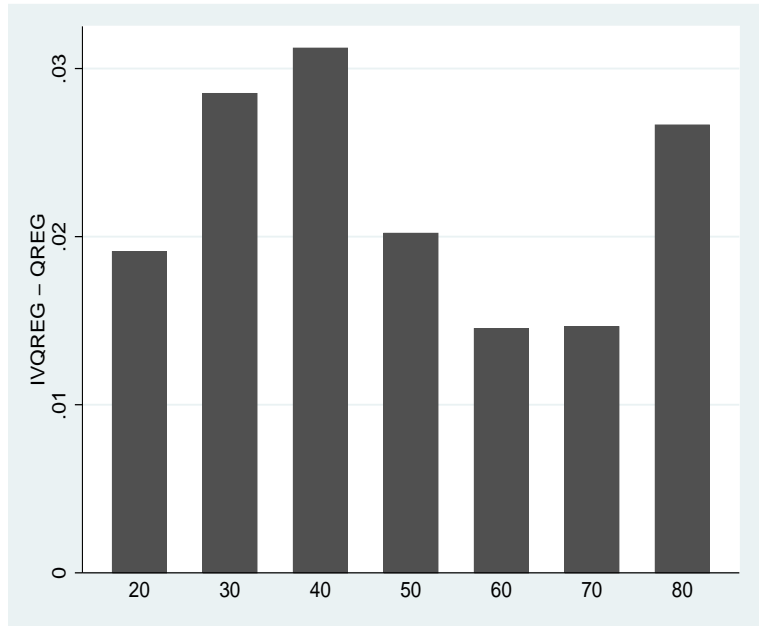

(d) Differences

Ordinary v.s. IV Quantile (2002)

Figure 4: Comparison among Quantile Results (Male Sample) 


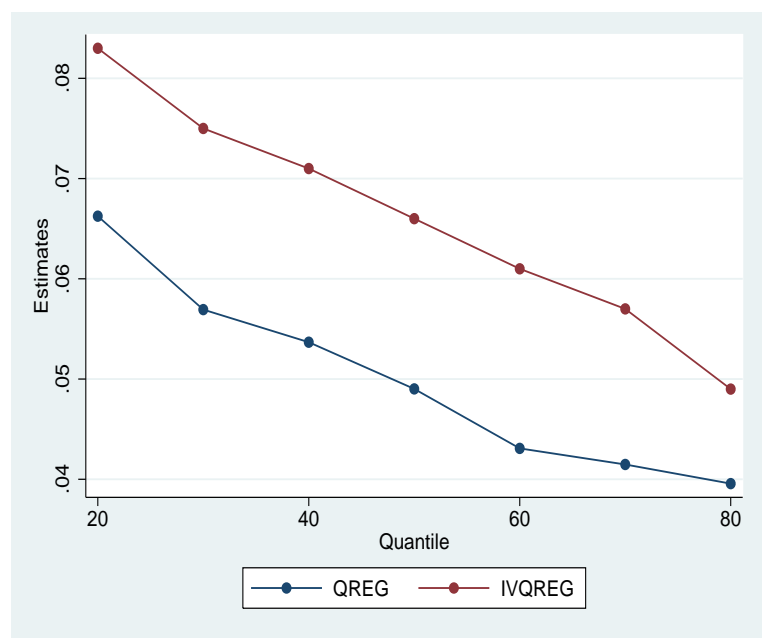

(a) Estimates

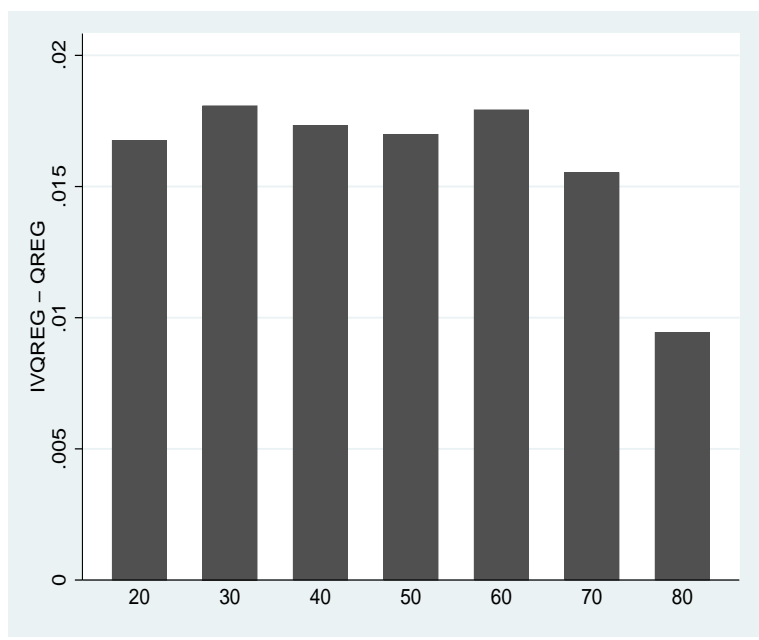

(b) Differences

Ordinary v.s. IV Quantile (1995)

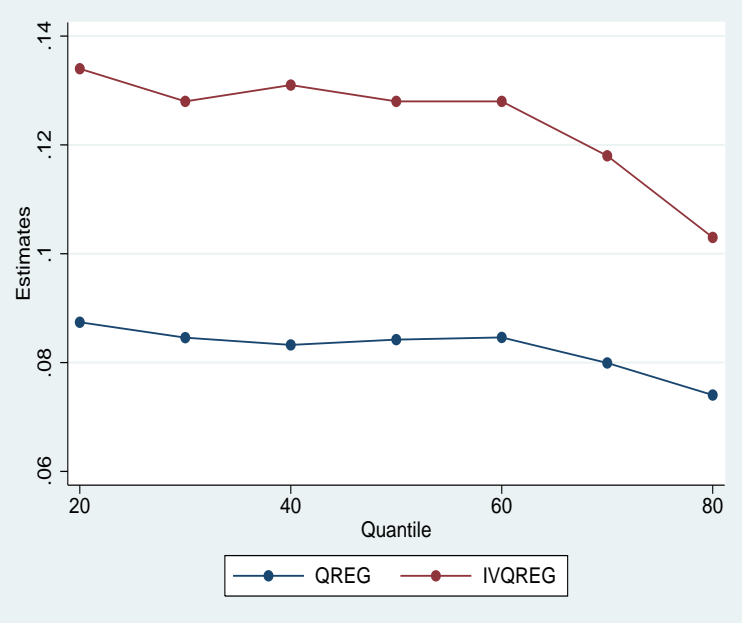

(c) Estimates

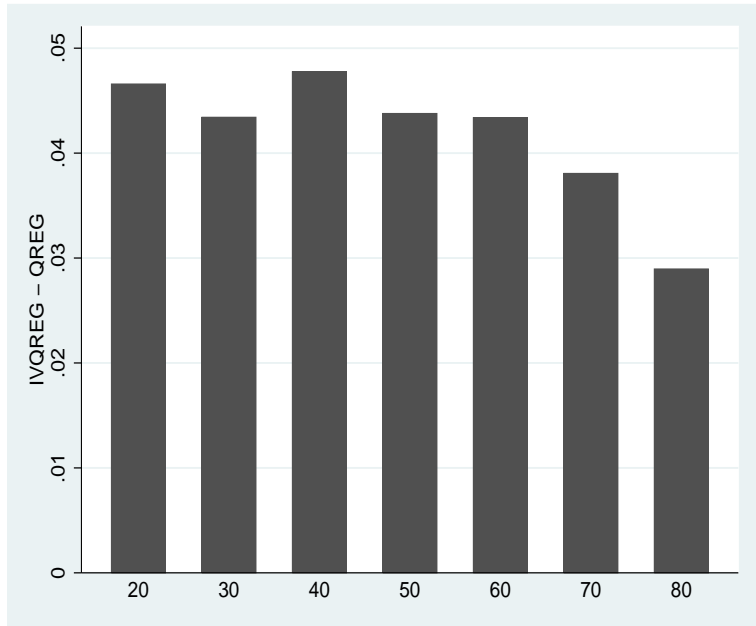

(d) Differences

Ordinary v.s. IV Quantile (2002)

Figure 5: Comparison among Quantile Results (Female Sample) 


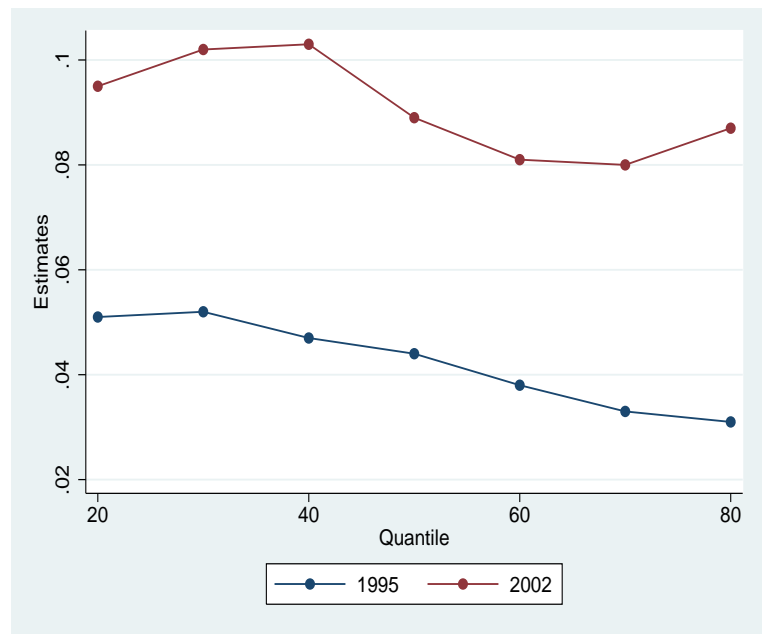

(a) Estimates

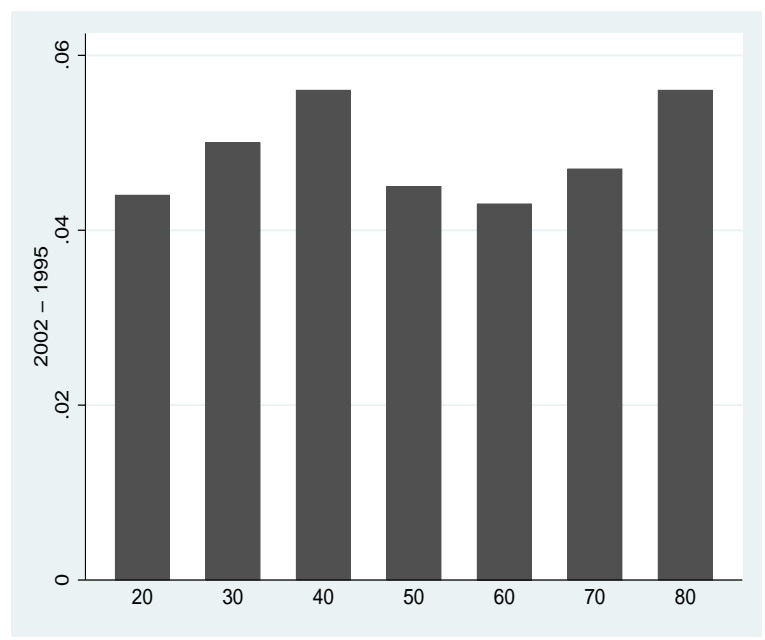

(b) Differences

Male Sample

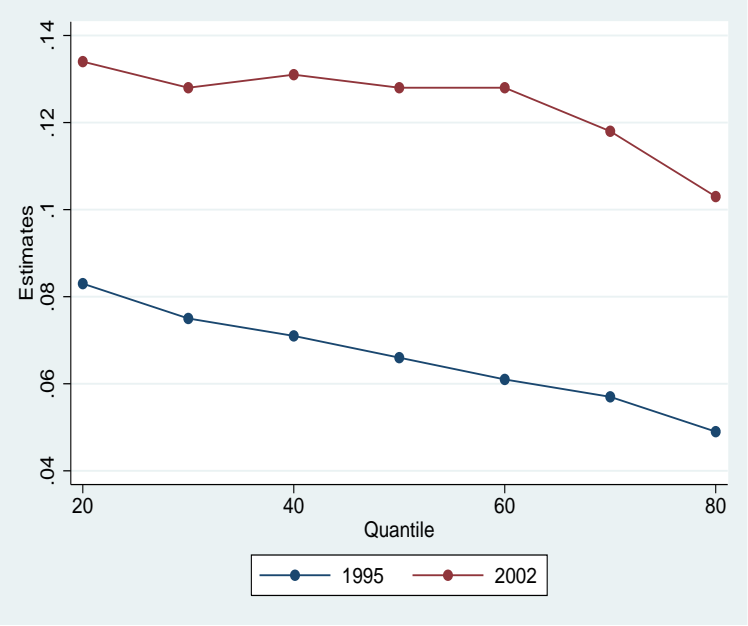

(c) Estimates

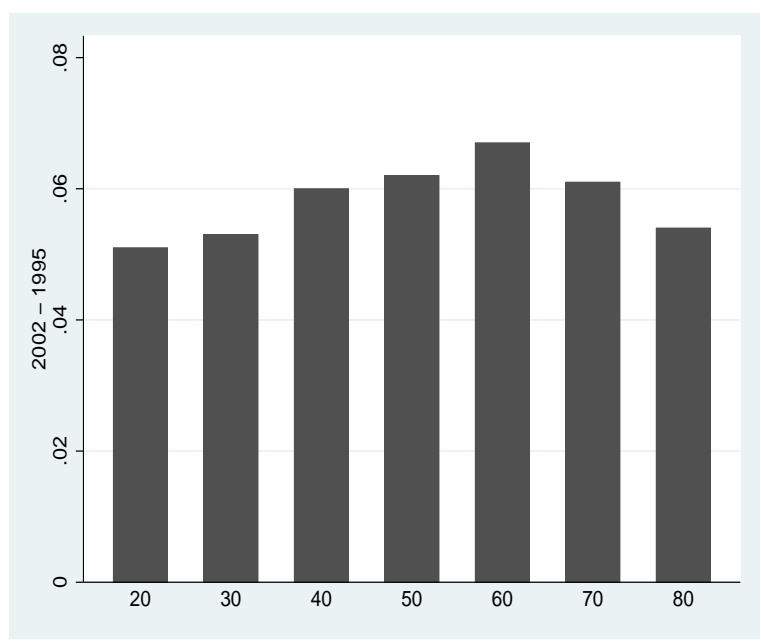

(d) Differences

Female Sample

Figure 6: Comparison of IVQR Results between 1995 and 2002 


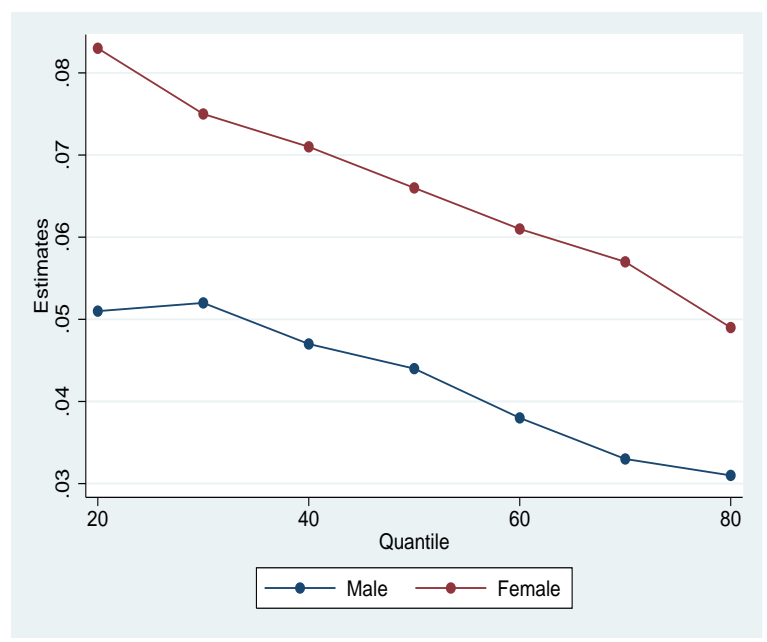

(a) Estimates

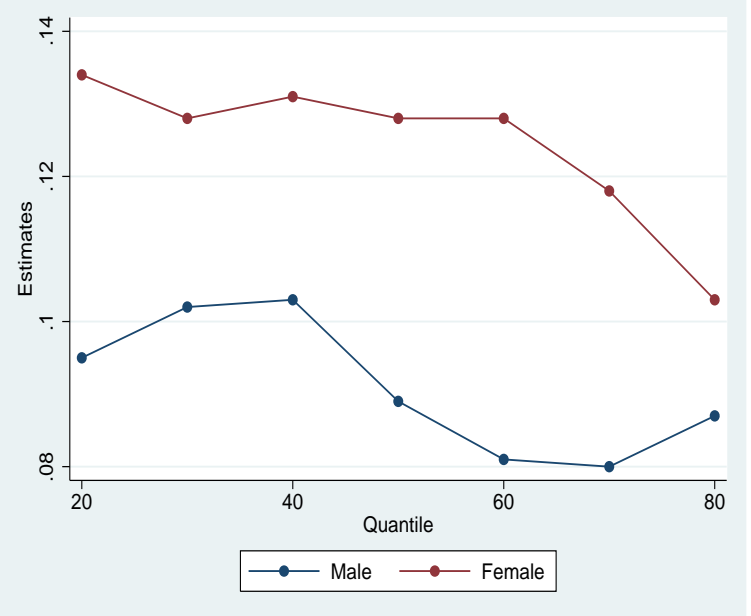

(c) Estimates

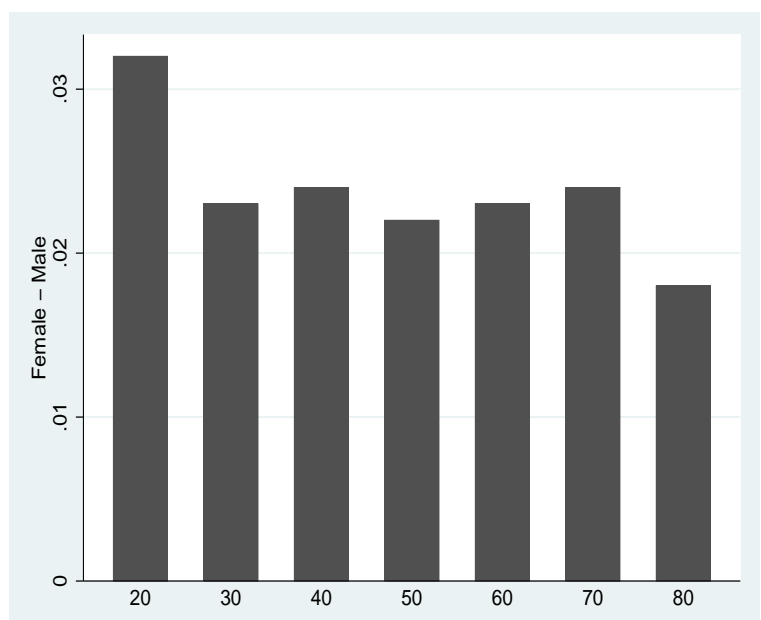

(b) Differences

1995

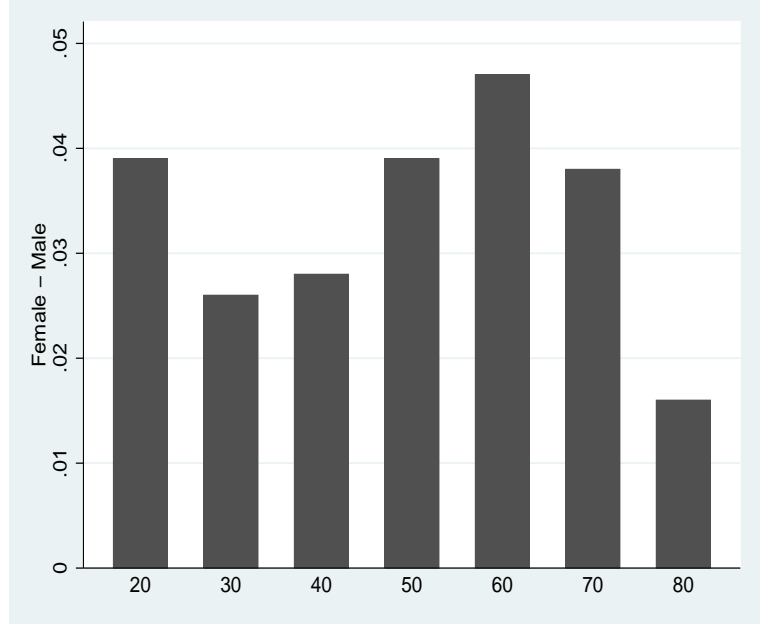

(d) Differences

2002

Figure 7: Comparison of IVQR Results between Female and Male 


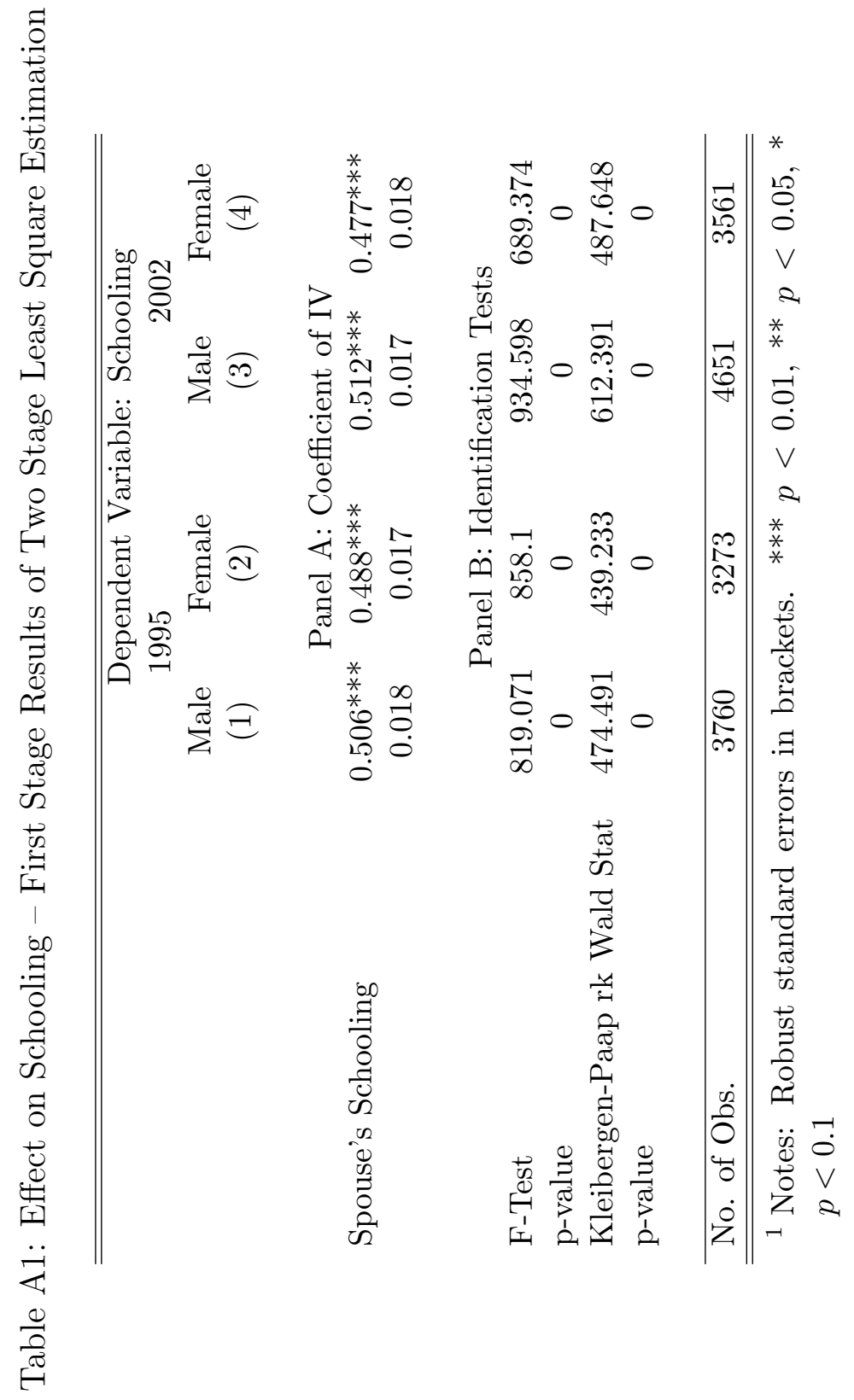


Table A2: Log Hourly Wage Results

\begin{tabular}{|c|c|c|c|c|c|c|c|c|}
\hline Year & $\begin{array}{c}\text { Mean } \\
(1)\end{array}$ & $\begin{array}{c}\tau=.2 \\
(2)\end{array}$ & $\begin{array}{c}\tau=.3 \\
(3)\end{array}$ & $\begin{array}{c}\tau=.4 \\
(4)\end{array}$ & $\begin{array}{c}\tau=.5 \\
(5)\end{array}$ & $\begin{array}{c}\tau=.6 \\
(6)\end{array}$ & $\begin{array}{c}\tau=.7 \\
(7)\end{array}$ & $\begin{array}{c}\tau=.8 \\
(8)\end{array}$ \\
\hline \multicolumn{9}{|c|}{ Panel A: Male Sample } \\
\hline & & & Panel & A.1: Ordin & ary Regress & ons & & \\
\hline 1995 & $\begin{array}{c}0.034^{* * *} \\
(0.002)\end{array}$ & $\begin{array}{c}0.044^{* * *} \\
(0.007)\end{array}$ & $\begin{array}{c}0.041^{* * *} \\
(0.007)\end{array}$ & $\begin{array}{c}0.04^{* * *} \\
(0.007)\end{array}$ & $\begin{array}{c}0.035^{* * *} \\
(0.007)\end{array}$ & $\begin{array}{c}0.028^{* * *} \\
(0.007)\end{array}$ & $\begin{array}{c}0.026^{* * *} \\
(0.007)\end{array}$ & $\begin{array}{c}0.023^{* * *} \\
(0.007)\end{array}$ \\
\hline 2002 & $\begin{array}{c}0.078^{* * *} \\
(0.003)\end{array}$ & $\begin{array}{c}0.084^{* * *} \\
(0.004)\end{array}$ & $\begin{array}{c}0.082^{* * *} \\
(0.004)\end{array}$ & $\begin{array}{c}0.084^{* * *} \\
(0.003)\end{array}$ & $\begin{array}{c}0.08^{* * *} \\
(0.003)\end{array}$ & $\begin{array}{c}0.076^{* * *} \\
(0.003)\end{array}$ & $\begin{array}{c}0.07^{* * *} \\
(0.003)\end{array}$ & $\begin{array}{c}0.07 * * * \\
(0.003)\end{array}$ \\
\hline \multicolumn{9}{|c|}{ Panel A.2: IV Regressions } \\
\hline 1995 & $\begin{array}{c}0.046^{* * *} \\
(0.006)\end{array}$ & $\begin{array}{c}0.055^{* * *} \\
(0.007)\end{array}$ & $\begin{array}{c}0.056^{* * *} \\
(0.007)\end{array}$ & $\begin{array}{c}0.058^{* * *} \\
(0.007)\end{array}$ & $\begin{array}{c}0.051^{* * *} \\
(0.007)\end{array}$ & $\begin{array}{c}0.045^{* * *} \\
(0.007)\end{array}$ & $\begin{array}{c}0.034^{* * *} \\
(0.007)\end{array}$ & $\begin{array}{c}0.03^{* * *} \\
(0.007)\end{array}$ \\
\hline 2002 & $\begin{array}{c}0.105^{* * *} \\
(0.006)\end{array}$ & $\begin{array}{c}0.123^{* * *} \\
(0.009)\end{array}$ & $\begin{array}{c}0.121^{* * *} \\
(0.008)\end{array}$ & $\begin{array}{c}0.113^{* * *} \\
(0.008)\end{array}$ & $\begin{array}{c}0.102^{* * * *} \\
(0.007)\end{array}$ & $\begin{array}{c}0.092^{* * *} \\
(0.007)\end{array}$ & $\begin{array}{c}0.087^{* * *} \\
(0.007)\end{array}$ & $\begin{array}{c}0.092^{* * *} \\
(0.007)\end{array}$ \\
\hline \multicolumn{9}{|c|}{ Panel B: Female Sample } \\
\hline \multicolumn{9}{|c|}{ Panel B.1: Ordinary Regressions } \\
\hline 1995 & $\begin{array}{c}0.054^{* * *} \\
(0.003)\end{array}$ & $\begin{array}{c}0.044^{* * *} \\
(0.003)\end{array}$ & $\begin{array}{c}0.041^{* * *} \\
(0.003)\end{array}$ & $\begin{array}{c}0.04^{* * *} \\
(0.003)\end{array}$ & $\begin{array}{c}0.035^{* * *} \\
(0.002)\end{array}$ & $\begin{array}{c}0.028^{* * *} \\
(0.003)\end{array}$ & $\begin{array}{c}0.026^{* * *} \\
(0.003)\end{array}$ & $\begin{array}{c}0.023^{* * *} \\
(0.003)\end{array}$ \\
\hline 2002 & $\begin{array}{c}0.092^{* * *} \\
(0.004)\end{array}$ & $\begin{array}{c}0.084^{* * *} \\
(0.004)\end{array}$ & $\begin{array}{c}0.082^{* * *} \\
(0.004)\end{array}$ & $\begin{array}{c}0.084^{* * *} \\
(0.003)\end{array}$ & $\begin{array}{c}0.08^{* * *} \\
(0.003)\end{array}$ & $\begin{array}{c}0.076^{* * *} \\
(0.003)\end{array}$ & $\begin{array}{c}0.07^{* * *} \\
(0.003)\end{array}$ & $\begin{array}{c}0.07^{* * *} \\
(0.003)\end{array}$ \\
\hline \multicolumn{9}{|c|}{ Panel B.2: IV Regressions } \\
\hline 1995 & $\begin{array}{c}0.080 * * * \\
(0.006)\end{array}$ & $\begin{array}{c}0.087^{* * *} \\
(0.007)\end{array}$ & $\begin{array}{c}0.084^{* * *} \\
(0.007)\end{array}$ & $\begin{array}{c}0.078 * * * \\
(0.008)\end{array}$ & $\begin{array}{c}0.073^{* * *} \\
(0.008)\end{array}$ & $\begin{array}{c}0.066^{* * *} \\
(0.008)\end{array}$ & $\begin{array}{c}0.063^{* * *} \\
(0.008)\end{array}$ & $\begin{array}{c}0.051^{* * *} \\
(0.008)\end{array}$ \\
\hline 2002 & $\begin{array}{c}0.133^{* * *} \\
(0.007)\end{array}$ & $\begin{array}{c}0.142^{* * *} \\
(0.011)\end{array}$ & $\begin{array}{c}0.14^{* * *} \\
(0.01)\end{array}$ & $\begin{array}{c}0.138^{* * *} \\
(0.01)\end{array}$ & $\begin{array}{c}0.131^{* * *} \\
\quad(0.01)\end{array}$ & $\begin{array}{c}0.13^{* * *} \\
(0.01)\end{array}$ & $\begin{array}{c}0.114^{* * *} \\
(0.009)\end{array}$ & $\begin{array}{c}0.114^{* * *} \\
(0.009)\end{array}$ \\
\hline
\end{tabular}

${ }^{1}$ Notes: Robust standard errors in brackets. ${ }^{* * *} p<0.01,{ }^{* *} p<0.05,{ }^{*}$ 